\title{
A New Series of Glycopeptide Antibiotics Incorporating a Squaric Acid Moiety
}

\author{
Synthesis, Structural and Antibacterial Studies ${ }^{\dagger}$
}

\author{
Ferenc Sztaricskai, Gyula Batta, Pál Herczegh, Attila Balázs, József Jeko, Erzsébet Roth, \\ Pál T. Szabó, Szilvia Kardos, Ferenc Rozgonyi, Zoltán Boda
}

Dedicated to the memory of Professor Kenneth L. Rinehart.

Received: May 8, 2006 / Accepted: September 14, 2006

(C) Japan Antibiotics Research Association

\begin{abstract}
The aglycones of the antibiotics eremomycin, vancomycin and ristocetin (3, 4 and $\mathbf{6}$, respectively) were prepared by deglycosidation of the parent antibiotics with hydrogen fluoride, and complete assignation of their ${ }^{1} \mathrm{H},{ }^{13} \mathrm{C}$ and ${ }^{15} \mathrm{~N}$ spectra was performed. The squaric acid amide esters $(\mathbf{1 1} \sim \mathbf{1 4})$, were prepared from dimethyl squarate. The corresponding asymmetric diamides (16 $\sim 19$, 22, 23) were also synthesized using 4-phenylbenzylamine and triglycine. The advantage of the method is the high regioselectivity and that no protecting group strategy is required. Electrospray mass spectroscopic method was elaborated for the determination of the site of substitution of the modified antibiotics. The antibacterial activity of the prepared compounds is discussed in detail.
\end{abstract}

Keywords synthesis, glycopeptide antibiotics, squaric acid amides, antibacterial

\section{Introduction}

During the past fifty years the chemistry, biology, and therapeutic application of the glycopeptide antibiotics have been continuously progressing $[1,2]$. In each of these antibiotics the specific heptapeptide aglycone is substituted at the alcoholic and/or phenolic hydroxyl groups with aminodeoxy sugars and simple, neutral carbohydrates. Based on the substitution pattern, mono-, bis-, tris-, and tetraglycoside-type glycopeptide antibiotics are classified [3], of which the bis- and tris-glycosides are the most frequently occurring. Until now, no $C$ - or $N$-glycosidic bond, or a glycosylamine structural unit were detected in the molecules of the glycopeptide antibiotics.

These antibiotics exert biological activity by developing hydrogen bond between the glycopeptide backbone and the L-Lys-D-Ala-D-Ala terminal monomer fragment of the peptidoglycan constituent in the bacterial cell wall. This interaction inhibits the transglycosidation and transpeptidation processes which leads to interruption of
F. Sztaricskai (Corresponding author), G. Batta, P. Herczegh, A. Balázs, J. Jeko, E. Roth: Research Group for Antibiotics of the Hungarian Academy of Sciences, and Department of Pharmaceutical Chemistry, University of Debrecen, H-4010 Debrecen, P.O.Box 70, Hungary, E-mail: sztarife@delfin.unideb.hu P. T. Szabó: Department of Biochemical Pharmacology, Chemical Research Center, H-1525 Budapest, P.O. Box 17, Hungary
S. Kardos, F. Rozgonyi: Institute of Medicinal Microbiology, Semmelweis University, H-1445, Budapest, P.O.Box 370, Hungary Z. Boda: IInd Department of Medicine, University of Debrecen, H-4012 Debrecen, P.O.Box 58, Hungary

${ }^{\dagger}$ A part of this work was presented at the 9th International Conference on the Chemistry of Antibiotics and other Bioactive Compounds, Bordeaux-Arcachon, France, 25-29 September, 2005. (Abstract No 30) 
the cell-wall synthesis and destruction of the bacteria. Interestingly, many glycopeptide antibiotics [vancomycin (2), eremomycin (1), ristocetin A (5), etc.] form dimeric complexes in aqueous solution [4].

Preparation of the aglycones of the glycopeptide antibiotics has been attempted by means of chemical methods, i.e. by acid hydrolysis of the parent antibiotics under various conditions. However, these procedures generally led to extremely complex reaction mixtures and low yields. The hydrogen fluoride-method was used by Wanner [5] in glycopeptide chemistry for the deglycosidation of vancomycin, ristocetin and ramoplanin.

In the present work we describe the results obtained by repeating deglycosidation of vancomycin and ristocetin A with hydrogen fluoride, and this procedure was also extended to eremomycin. For comparison of the NMR spectra, the aglycone of teicoploanin was also prepared by acid hydrolysis (Fig. 1). The synthesis, physico-chemical

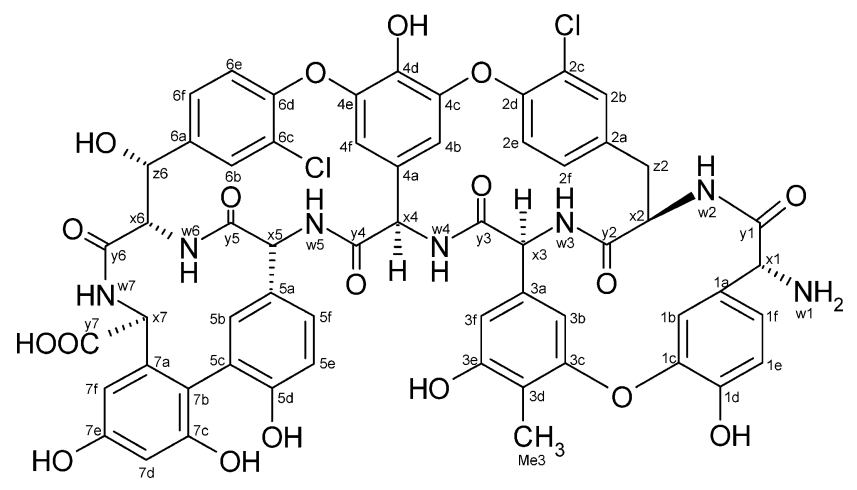

Fig. 1 Structure of aglyco-teicoplanin. properties, mass and NMR spectral characteristics and antibacterial activity of the new semisynthetic glycopeptide antibiotics and their aglycones prepared with dimethyl squarate are also presented.

\section{Results and Discussion}

\section{Deglycosidation}

The cleavage of the $O$-glycosidic bond of the glycopeptide antibiotics with hydrogen fluoride is greatly influenced by several factors, including the type and number of places of attachments of the neutral sugars and aminodeoxy hexoseseither as a monosaccharide unit or an oligosaccharide chain-to the heptapeptide aglycones.

We observed that deglycosidation of the monoglycosidetype vancomycin (2) and of the bis-glycoside-type eremomycin (1) with HF/anisole under the conditions suggested by the American researchers [5] (Scheme 1) furnished the homogeneous aglyco-vancomycin (4) and aglyco-eremomycin (3) with good yields. The purity of the products was proved by TLC, HPLC, and MALDI-TOF (Table 1), and the structures were assigned according to the ${ }^{1} \mathrm{H}$ and ${ }^{13} \mathrm{C}$ NMR data (Table $2 \mathrm{a} \sim \mathrm{b}$ ). The yields of the reactions were greatly influenced by the temperature and volume of the EtOAc-MeOH mixture $(4: 1)$ used for washing in work-up procedure.

In contrast to the data described for $\mathbf{1}$ and $\mathbf{2}$, deglycosidation of the tris-glycoside-type ristocetin A (5), containing six carbohydrate units, with anhydrous HFanisol mixture (Scheme 2) resulted in 3 4 component reaction mixtures in each case. Purification of the

Table 1 Physico-chemical properties of the aglycones

\begin{tabular}{|c|c|c|c|c|c|c|c|c|c|}
\hline & \multirow[b]{2}{*}{$\begin{array}{l}\text { Name of the } \\
\text { aglycones }\end{array}$} & \multirow[b]{2}{*}{ Yield \% } & \multirow[b]{2}{*}{$\begin{array}{l}\text { HPLC } \\
\mathrm{R}_{\mathrm{t} \min }\end{array}$} & \multirow[b]{2}{*}{$\begin{array}{l}\text { TLC } \\
\mathrm{Rf}\end{array}$} & \multicolumn{3}{|c|}{ Molecular weight } & \multirow[b]{2}{*}[\alpha]{$_{D}^{20}$} & \multirow[b]{2}{*}{$\begin{array}{c}\text { UV } \lambda_{\max } \\
\mathrm{nm}\end{array}$} \\
\hline & & & & & $\begin{array}{c}\text { Formula of the } \\
\text { aglycones }\end{array}$ & Calculated & $\begin{array}{c}\text { Measured } \\
\text { MALDI-TOF } \\
(\mathrm{M}+\mathrm{Na})^{+}\end{array}$ & & \\
\hline 3 & Eremomycin & 57.8 & 13.70 & (1 A) 0.51 & $\mathrm{C}_{53} \mathrm{H}_{53} \mathrm{O}_{17} \mathrm{~N}_{8} \mathrm{Cl}$ & 1109 & 1131.5 & $\begin{array}{c}92.1 \\
(c=0.10 \mathrm{MeOH})\end{array}$ & $\begin{array}{c}279 \\
(\mathrm{MeOH})\end{array}$ \\
\hline 4 & Vancomycin & 89.87 & 14.68 & (1 A) 0.62 & $\mathrm{C}_{53} \mathrm{H}_{52} \mathrm{O}_{17} \mathrm{~N}_{8} \mathrm{Cl}_{2}$ & 1143 & 1165.3 & $\begin{array}{c}55.8 \\
(c=0.26 \mathrm{DMF})\end{array}$ & $\begin{array}{c}281 \\
(\mathrm{DMF})\end{array}$ \\
\hline 6 & Ristocetin-A & 52.8 & 14.60 & $\begin{array}{l}(1 \mathrm{~A}) 0.63 \\
(2 \mathrm{~B}) 0.26\end{array}$ & $\mathrm{C}_{60} \mathrm{H}_{51} \mathrm{O}_{19} \mathrm{~N}_{7}$ & 1173 & 1196.4 & $\begin{array}{c}-55.3 \\
(c=0.20 \mathrm{MeOH})\end{array}$ & $\begin{array}{c}279 \\
(\mathrm{MeOH})\end{array}$ \\
\hline
\end{tabular}

TLC: (1) DC Cellulose

(2) Kieselgel $60 \mathrm{~F}_{254}$
Solvent system: (A) $n \mathrm{BuOH}-\mathrm{Pyr}-\mathrm{AcOH}-\mathrm{H}_{2} \mathrm{O}(15: 10: 3: 12)$

(B) Toluene- $\mathrm{MeOH}-\mathrm{AcOH}(1: 1: 0.05)$

Detection: Pauly-reagent 


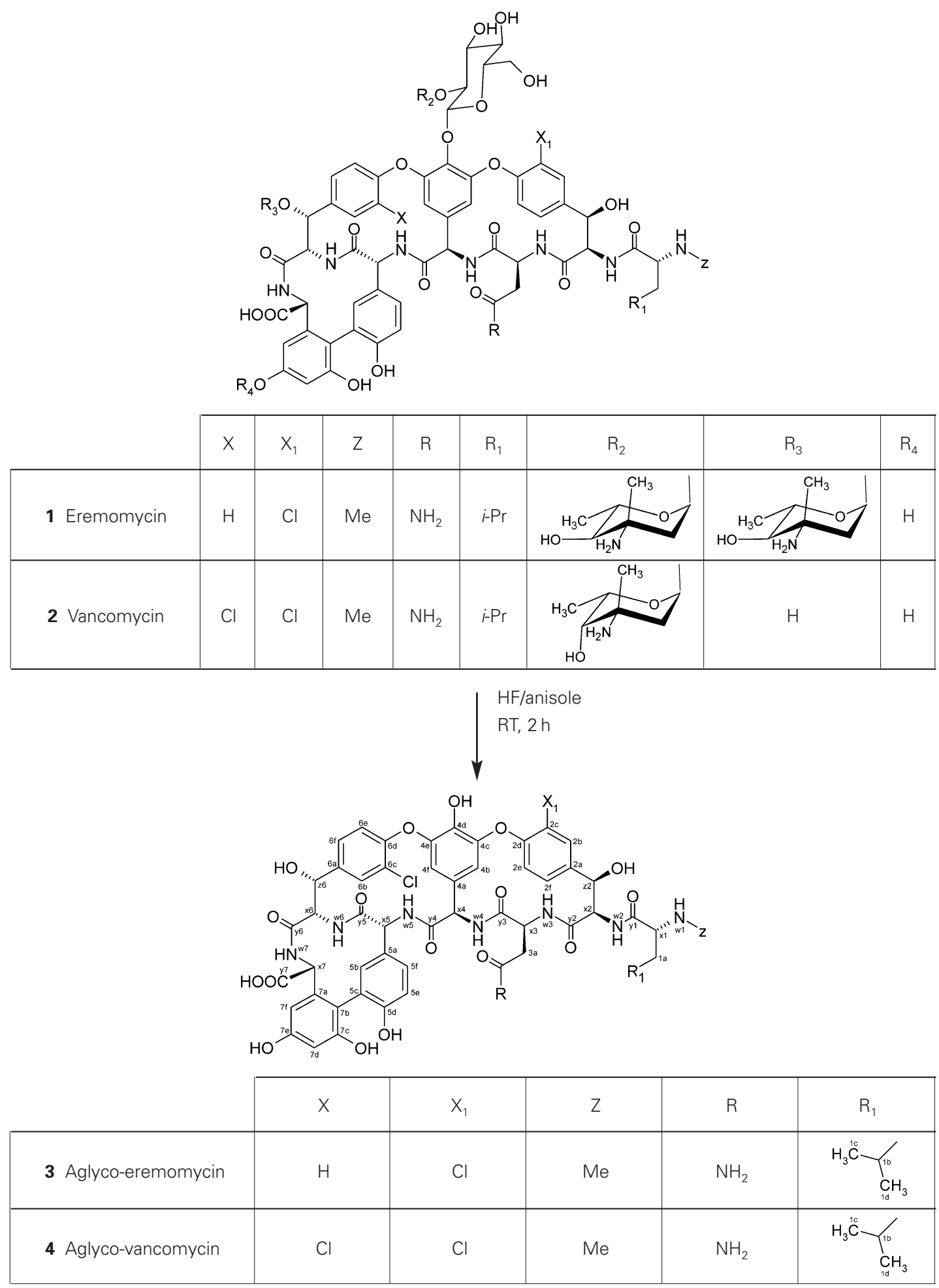

Scheme 1 Deglycosidation of eremomycin and vancomycin [5]. 
Table 2 NMR assignments of the the glycopeptide aglycones

(a) ${ }^{1} \mathrm{H} /{ }^{13} \mathrm{C}$ chemical shift assignment of the aglycones of eremomycin and vancomycin. Solvent reference signals were used for ${ }^{13} \mathrm{C}$ calibration: $\mathrm{DMSO}=39.51 \mathrm{ppm}$

\begin{tabular}{|c|c|c|c|c|c|}
\hline \multicolumn{3}{|c|}{ Aglycoeremomycin, DMSO, $340 \mathrm{~K}$} & \multicolumn{3}{|c|}{ Aglycovancomycin, DMSO, $330 \mathrm{~K}$} \\
\hline Assignment & ${ }^{1} \mathrm{H}$ (ppm) & ${ }^{13} \mathrm{C}(\mathrm{ppm})$ & Assignment & ${ }^{1} \mathrm{H}$ (ppm) & ${ }^{13} \mathrm{C}$ (ppm) \\
\hline $1 \mathrm{a}$ & $1.442 / 1.520$ & 41.51 & $1 a$ & $1.474 / 1.556$ & 40.62 \\
\hline $1 b$ & 1.791 & 24.23 & $1 b$ & 1.741 & 24.09 \\
\hline $1 \mathrm{c}$ & 0.908 & 22.13 & $1 c$ & 0.926 & 22.74 \\
\hline $1 d$ & 0.937 & 22.89 & $1 d$ & 0.889 & 22.31 \\
\hline $1 e$ & 2.338 & 34.09 & $1 e$ & 2.378 & 33.28 \\
\hline $2 a$ & - & 139.79 & $2 a$ & - & 139.66 \\
\hline $2 b$ & 7.464 & 128.35 & $2 b$ & 7.430 & 128.45 \\
\hline $2 c$ & - & 129.91 & $2 c$ & - & 126.94 \\
\hline $2 d$ & - & 150.37 & $2 d$ & - & 150.37 \\
\hline $2 e$ & 7.243 & 124.2 & $2 e$ & 7.280 & 124.31 \\
\hline $2 f$ & 7.542 & 126.63 & $2 f$ & 7.548 & 126.80 \\
\hline 3а & $2.149 / 2.644$ & 36.27 & $3 a$ & $2.170 / 2.542$ & 36.78 \\
\hline $4 a$ & - & 129.91 & $4 a$ & - & 128.73 \\
\hline $4 b$ & 5.404 & 106.31 & $4 b$ & 5.228 & 104.43 \\
\hline $4 c$ & - & 147.88 & $4 c$ & - & 147.70 \\
\hline $4 d$ & - & 134.41 & $4 d$ & - & 133.92 \\
\hline $4 e$ & - & 149.3 & $4 \mathrm{e}$ & - & 149.02 \\
\hline $4 f$ & 5.617 & 106.58 & $4 f$ & 5.633 & 107.02 \\
\hline $5 a$ & - & 126.93 & $5 a$ & - & 126.19 \\
\hline $5 b$ & 7.160 & 135.8 & $5 b$ & 7.172 & 135.64 \\
\hline $5 c$ & - & 126.34 & $5 c$ & - & 121.69 \\
\hline $5 d$ & - & 154.57 & $5 d$ & - & 154.95 \\
\hline $5 e$ & 6.714 & 116.24 & $5 e$ & 6.741 & 116.25 \\
\hline $5 f$ & 6.789 & 125.35 & $5 f$ & 6.802 & 125.37 \\
\hline $6 a$ & - & 139.69 & $6 a$ & - & 141.99 \\
\hline $6 b$ & 7.507 & 128.11 & $6 b$ & 7.854 & 127.46 \\
\hline $6 c$ & 7.093 & 120.63 & $6 c$ & - & 126.10 \\
\hline $6 d$ & - & 154.39 & $6 d$ & - & 147.49 \\
\hline $6 e$ & 6.888 & 121.65 & $6 e$ & 7.231 & 123.12 \\
\hline $6 f$ & 7.637 & 126.73 & $6 f$ & 7.471 & 127.12 \\
\hline $7 a$ & - & 136.57 & $7 a$ & - & 136.30 \\
\hline $7 b$ & - & 118.2 & $7 b$ & - & 117.99 \\
\hline $7 c$ & - & 156.28 & 7c & - & 156.34 \\
\hline $7 d$ & 6.390 & 102.36 & $7 d$ & 6.418 & 102.27 \\
\hline $7 e$ & - & 157 & $7 e$ & - & 157.07 \\
\hline $7 f$ & 6.363 & 106.19 & $7 f$ & 6.337 & 106.01 \\
\hline $\mathrm{X} 1$ & 3.024 & 62.33 & $\mathrm{X} 1$ & 3.217 & 61.69 \\
\hline$\times 2$ & 4.715 & 58.53 & $X 2$ & 4.825 & 58.52 \\
\hline X3 & 4.309 & 51.08 & X3 & 4.371 & 51.00 \\
\hline$X 4$ & 5.675 & 55.1 & $X 4$ & 5.713 & 54.64 \\
\hline$\times 5$ & 4.547 & 53.58 & $\times 5$ & 4.465 & 53.69 \\
\hline X6 & 4.211 & 62.15 & $x 6$ & 4.200 & 61.71 \\
\hline$x 7$ & 4.491 & 56.88 & $X 7$ & 4.488 & 56.84 \\
\hline y1 & - & 174.3 & y1 & - & 173.22 \\
\hline y2 & - & 171.8 & y2 & - & 171.37 \\
\hline y3 & - & 169.87 & y3 & - & 170.19 \\
\hline
\end{tabular}


Table 2 (a) (continued)

\begin{tabular}{|c|c|c|c|c|c|}
\hline \multicolumn{3}{|c|}{ Aglycoeremomycin, DMSO, $340 \mathrm{~K}$} & \multicolumn{3}{|c|}{ Aglycovancomycin, DMSO, $330 \mathrm{~K}$} \\
\hline Assignment & ${ }^{1} \mathrm{H}(\mathrm{ppm})$ & ${ }^{13} \mathrm{C}(\mathrm{ppm})$ & Assignment & ${ }^{1} \mathrm{H}(\mathrm{ppm})$ & ${ }^{13} \mathrm{C}$ (ppm) \\
\hline y4 & - & 169.18 & y4 & - & 169.34 \\
\hline y5 & - & 169.08 & y5 & - & 169.22 \\
\hline y6 & - & 167.02 & y6 & - & 167.01 \\
\hline y7 & - & 167.61 & y7 & - & 167.46 \\
\hline y8 (Asp) & - & 172.39 & y8 (Asp) & - & 172.47 \\
\hline $\mathrm{Z} 2$ & 5.139 & 71.5 & $\mathrm{Z} 2$ & 5.171 & 71.27 \\
\hline Z6 & 5.195 & 71.82 & Z6 & 5.150 & 71.45 \\
\hline
\end{tabular}

(b) ${ }^{1} \mathrm{H} /{ }^{15} \mathrm{~N}$ chemical shift assignment of the aglycones of eremomycin and vancomycin. ${ }^{15} \mathrm{~N}$ chemical shift scale is derived indirectly from solvent ${ }^{1} \mathrm{H}$ chemical shifts (2.50 ppm for DMSO) and the known gyromagnetic ratios of ${ }^{1} \mathrm{H}$ and ${ }^{15} \mathrm{~N}$ nuclei

\begin{tabular}{|c|c|c|c|c|c|}
\hline \multicolumn{3}{|c|}{ Aglycoeremomycin, DMSO, $340 \mathrm{~K}$} & \multicolumn{3}{|c|}{ Aglycovancomycin, DMSO, $330 \mathrm{~K}$} \\
\hline Assignment & ${ }^{1} \mathrm{H}$ (ppm) & ${ }^{15} \mathrm{~N}(\mathrm{ppm})$ & Assignment & ${ }^{1} \mathrm{H}(\mathrm{ppm})$ & ${ }^{15} \mathrm{~N}(\mathrm{ppm})$ \\
\hline w2 & 8.560 & 121.25 & w2 & (8.335) & (121.48) \\
\hline w3 & 6.263 & 118.60 & w3 & 6.559 & 117.55 \\
\hline w4 & 8.105 & 120.85 & w4 & 8.077 & 118.50 \\
\hline w5 & 8.633 & 123.97 & w5 & 8.494 & 123.65 \\
\hline w6 & 6.468 & 107.13 & w6 & 6.572 & 106.65 \\
\hline w7 & 8.556 & 126.50 & w7 & 8.452 & 126.99 \\
\hline $\mathrm{NH}_{2}$ (Asp) & $6.964 / 7.406$ & 110.84 & $\mathrm{NH}_{2}$ (Asp) & $6.817 / 7.284$ & 110.14 \\
\hline
\end{tabular}

(c) ${ }^{1} \mathrm{H} /{ }^{13} \mathrm{C}$ chemical shift assignment of the aglycones of ristocetin and teicoplanin. Solvent reference signals were used for ${ }^{13} \mathrm{C}$ calibration $\mathrm{CD}_{3} \mathrm{OD}=49.15 \mathrm{DMSO}=39.51 \mathrm{ppm}$

\begin{tabular}{|c|c|c|c|c|c|}
\hline \multicolumn{3}{|c|}{ Aglycoristocetin, $\mathrm{CD}_{3} \mathrm{OD}, 300 \mathrm{~K}$} & \multicolumn{3}{|c|}{ Aglycoteicoplanin, DMSO, $330 \mathrm{~K}$} \\
\hline Assignment & ${ }^{1} \mathrm{H}(\mathrm{ppm})$ & ${ }^{13} \mathrm{C}(\mathrm{ppm})$ & Assignment & ${ }^{1} \mathrm{H}$ (ppm) & ${ }^{13} \mathrm{C}$ (ppm) \\
\hline $1 a$ & - & 125.30 & $1 a$ & - & 131.48 \\
\hline $1 b$ & 6.774 & 118.39 & $1 b$ & 6.682 & 117.45 \\
\hline $1 c$ & - & 145.04 & $1 c$ & - & 141.47 \\
\hline $1 d$ & - & 150.81 & $1 d$ & - & 146.83 \\
\hline $1 e$ & 6.925 & 119.23 & $1 e$ & 6.936 & 118.25 \\
\hline $1 f$ & 7.096 & 124.31 & $1 f$ & 7.125 & 124.89 \\
\hline $2 a$ & - & 137.68 & $2 a$ & - & 135.42 \\
\hline $2 b$ & 7.908 & 130.97 & $2 b$ & 7.22 & 130.90 \\
\hline $2 c$ & 7.158 & 129.05 & $2 c$ & - & 126.11 \\
\hline $2 d$ & - & 157.22 & $2 d$ & - & 150.68 \\
\hline $2 e$ & 7.118 & 128.25 & $2 e$ & 7.224 & 124.55 \\
\hline $2 f$ & 7.161 & 124.18 & $2 f$ & 7.646 & 129.87 \\
\hline 3а & - & 138.45 & $3 a$ & - & 140.70 \\
\hline $3 b$ & 6.482 & 110.03 & $3 b$ & 6.359 & 110.01 \\
\hline $3 c$ & - & 157.35 & $3 c$ & - & 158.44 \\
\hline $3 d$ & - & 115.12 & $3 d$ & 6.340 & 104.87 \\
\hline
\end{tabular}


Table 2 (c) (continued)

\begin{tabular}{|c|c|c|c|c|c|}
\hline \multicolumn{3}{|c|}{ Aglycoristocetin, $\mathrm{CD}_{3} \mathrm{OD}, 300 \mathrm{~K}$} & \multicolumn{3}{|c|}{ Aglycoteicoplanin, DMSO, $330 \mathrm{~K}$} \\
\hline Assignment & ${ }^{1} \mathrm{H}(\mathrm{ppm})$ & ${ }^{13} \mathrm{C}$ (ppm) & Assignment & ${ }^{1} \mathrm{H}(\mathrm{ppm})$ & ${ }^{13} \mathrm{C}(\mathrm{ppm})$ \\
\hline $3 e$ & - & 158.79 & $3 e$ & - & 157.10 \\
\hline $3 f$ & 6.630 & 106.1 & $3 f$ & 6.40 & 102.66 \\
\hline $4 a$ & - & 129.2 & $4 a$ & - & 127.61 \\
\hline $4 b$ & 5.785 & 107.86 & $4 b$ & 5.568 & 107.18 \\
\hline $4 c$ & - & 150.89 & $4 c$ & - & 147.61 \\
\hline $4 d$ & - & 135.95 & $4 d$ & - & 134.19 \\
\hline $4 e$ & - & 150.69 & $4 e$ & - & 147.50 \\
\hline $4 f$ & 5.378 & 106.87 & $4 f$ & 5.147 & 104.30 \\
\hline $5 a$ & - & 127.44 & $5 a$ & & 125.83 \\
\hline $5 b$ & 7.06 & 137.58 & $5 b$ & 7.123 & 135.53 \\
\hline $5 c$ & - & 121.92 & $5 c$ & - & 121.13 \\
\hline $5 d$ & - & 156.94 & $5 d$ & - & 155.40 \\
\hline $5 e$ & 6.822 & 121.42 & $5 e$ & 6.670 & 116.52 \\
\hline $5 f$ & 6.851 & 128.21 & $5 f$ & 6.72 & 125.66 \\
\hline $6 a$ & - & 139.94 & $6 a$ & - & 142.04 \\
\hline $6 b$ & 7.427 & 127.65 & $6 b$ & 7.800 & 127.16 \\
\hline $6 c$ & 6.882 & 122.68 & $6 c$ & - & 127.51 \\
\hline $6 d$ & - & 156.8 & $6 d$ & - & 148.63 \\
\hline $6 e$ & 6.796 & 123.45 & $6 e$ & 7.234 & 123.08 \\
\hline $6 f$ & 7.479 & 129.45 & $6 f$ & 7.466 & 127.22 \\
\hline $7 a$ & - & 137.02 & $7 a$ & - & 136.14 \\
\hline $7 b$ & - & 118.83 & $7 b$ & - & 117.69 \\
\hline 7c & - & 157.76 & 7c & - & 156.35 \\
\hline $7 d$ & 6.515 & 104.36 & $7 d$ & 6.40 & 102.66 \\
\hline $7 e$ & - & 159.22 & $7 e$ & - & 157.30 \\
\hline $7 f$ & 6.277 & 107.91 & $7 f$ & 6.292 & 105.94 \\
\hline $\mathrm{X} 1$ & 5.409 & 57.6 & $\mathrm{X} 1$ & 4.587 & 57.92 \\
\hline$\times 2$ & 5.401 & 62.87 & $X 2$ & 5.02 & 54.27 \\
\hline X3 & 5.459 & 60.2 & X3 & 5.358 & 57.94 \\
\hline$\times 4$ & 5.778 & 56.09 & $X 4$ & 5.631 & 54.84 \\
\hline$\times 5$ & 4.528 & 55.49 & $\times 5$ & 4.384 & 53.53 \\
\hline$x 6$ & 4.147 & 64.63 & $x 6$ & 4.14 & 61.63 \\
\hline$\times 7$ & 4.790 & 58.34 & X7 & 4.459 & 56.63 \\
\hline $\mathrm{y} 1$ & - & 171.81 & y1 & - & 173.21 \\
\hline y2 & - & 171.26 & y2 & - & 169.06 \\
\hline y3 & - & 172.18 & y3 & - & 168.01 \\
\hline y4 & - & 171.08 & y4 & - & 170.05 \\
\hline y5 & - & 171.81 & y5 & - & 169.06 \\
\hline y6 & - & 170.64 & y6 & - & 167.35 \\
\hline y7 & - & 173.77 & y7 & - & 172.25 \\
\hline $\mathrm{Z} 2$ & 5.076 & 73.29 & $\mathrm{Z} 2$ & 2.869/3.321 & 36.69 \\
\hline Z6 & 5.376 & 73.37 & Z6 & 5.117 & 71.40 \\
\hline Me3 & 1.960 & 8.45 & & & \\
\hline Me7 (OMe) & 3.831 & 52.99 & & & \\
\hline
\end{tabular}


Table 2 (continued)

(d) ${ }^{1} \mathrm{H} /{ }^{15} \mathrm{~N}$ chemical shift assignment of the aglyconeees of ristocetin and teicoplanin. ${ }^{15} \mathrm{~N}$ chemical shift scale is derived indirectly from solvent ${ }^{1} \mathrm{H}$ chemical shifts (3.31 for $\mathrm{CD}_{3} \mathrm{OD}$ and $2.50 \mathrm{ppm}$ for DMSO) and the known gyromagnetic ratios of ${ }^{1} \mathrm{H}$ and ${ }^{15} \mathrm{~N}$ nuclei

\begin{tabular}{|c|c|c|c|c|c|}
\hline Assignment & ${ }^{1} \mathrm{H}$ (ppm) & ${ }^{15} \mathrm{~N}(\mathrm{ppm})$ & Assignment & ${ }^{1} \mathrm{H}$ (ppm) & ${ }^{15} \mathrm{~N}(\mathrm{ppm})$ \\
\hline w2 & 10.297 & 112.80 & w2 & 7.395 & 116.06 \\
\hline (w3) & 9.305 & 118.17 & w3 & 7.627 & 118.75 \\
\hline w6 & 7.135 & 108.47 & w6 & 6.571 & 106.66 \\
\hline w7 & 8.948 & 127.87 & w7 & 8.316 & 126.40 \\
\hline
\end{tabular}

inhomogeneous crude product on a Silicagel 60 column (see Experimental) furnished aglyco-ristocetin A (6) which was homogeneous as shown by TLC, HPLC and MALDITOF mass spectrometry (Table 1), as well as by means of ${ }^{1} \mathrm{H}$ and ${ }^{13} \mathrm{C}$ NMR assignments (Table $2 \mathrm{c} \sim \mathrm{d}$ ).

Characterization of $\mathbf{6}$ was very important in the knowledge of the results reported by Ellestad et al. [6], who observed epimerization of the methin-group of the $\mathrm{N}$-terminal-4hydroxyphenylglycine unit of avoparcins. In addition, Herrin et al. [7] performed inversion of the configuration at the $N$-terminal amino group of aglyco-ristocetin A (ring of ristomycinic acid) by a chemical method to obtain epiaglyco-ristocetin A (7). Thus the $R$ configuration of the named asymmetric center in $\mathbf{6}$ changed to $S$ in 7 .

\section{Preparation of Semisynthetic Glycopeptide Antibiotics}

The goal of the development of new series of the glycopeptide antibiotics is to produce analogues active against methicillin-resistant Staphylococcus aureus (MRSA) and vancomycin-resistant Enterococcus faecalis (VREF) strains.

In a recent work we have successfully applied squaric acid esters, introduced by Tietze et al. [8], for the chemical modification of anthracycline glycoside antibiotics $[9,10]$. It is known that squaric esters (7) selectively react with a small excess of primary or secondary amines in aqueous and/or alcoholic media even in the presence of alcoholic and phenolic hydroxyl, and also carboxyl groups. In neutral media the product is always the squaric acid amide ester $(8)$, whereas under more alkaline conditions $(\mathrm{pH}>7)$ the corresponding symmetric (9) or asymmetric diamide (10) are produced (Scheme 3).

The reaction of the amino functions of the glycopeptide antibiotics located at $\mathrm{N}$-terimus of the heptapeptide aglycones and at the aminodeoxy sugars with a squaric acid ester would afford mono and diamide or triamide derivatives. The diamides may possess symmetric or asymmetric structure. The primary and secondary $N$-terminal amino groups of the aglycones are always more reactive than the amino function of the aminodeoxy sugar moieties.

The reaction of the antibiotics $\mathbf{1 , 2}$ and $\mathbf{5}$ with the squaric acid ester 7, furnished (Scheme 4) the squaric acid amide esters 11, 12 and 13, which spontaneously separated from the reaction mixtures. Due to the slight water-solubility of $\mathbf{6}$, analogous reaction gave the $\mathbf{1 4}$ amide ester of aglycoristocetin A only in a 1:1 methanol-buffer $(\mathrm{pH} \sim 7)$ mixture. The best yields were obtained with $\mathbf{5}$ and $\mathbf{6}$, carrying an $N$-terminal primary amino group, to give the squaric acid amide estes $\mathbf{1 3}$ and $\mathbf{1 4}$ of ristomycin $\mathrm{A}$ and aglyco-ristomycin $\mathrm{A}$, respectively.

The homogenity/purity of the above squaric acid amide esters was investigated by TLC and HPLC, and their structures were substantiated by means of MALDI-TOF mass spectrometry, the UV spectral data $\left(\lambda_{\max }=277 \sim\right.$ $281 \mathrm{~nm}$ ), characteristic of the glycopeptide antibiotics (Table 3), and by the ${ }^{1} \mathrm{H}$ and ${ }^{13} \mathrm{C}$ NMR spectra (Table 5).

Theoretically, it cannot be excluded that besides hydrogen-bonding, the antibiotic squaric acid amide esters 11 14 can bind to the peptidoglycan fragment of the bacterial cell wall also with covalent bonding at an appropriate $\mathrm{pH}$.

Of the numerous, known semisynthetic derivatives [2, 11 16] the most active are those in which the amino group of the heterodisaccharide side-chain is substituted either with a bulky aromatic group, or a longer alkyl chain. We decided to enhance the lipophilic character of the glycopeptide molecules by reacting compounds $\mathbf{1 1} \sim \mathbf{1 4}$ with 4-phenylbenzylamine (15) to furnish the asymmetric diamides 16 19 (Scheme 4). The characteristic physicochemical and NMR data are summarized in Tables 4 and 5, 


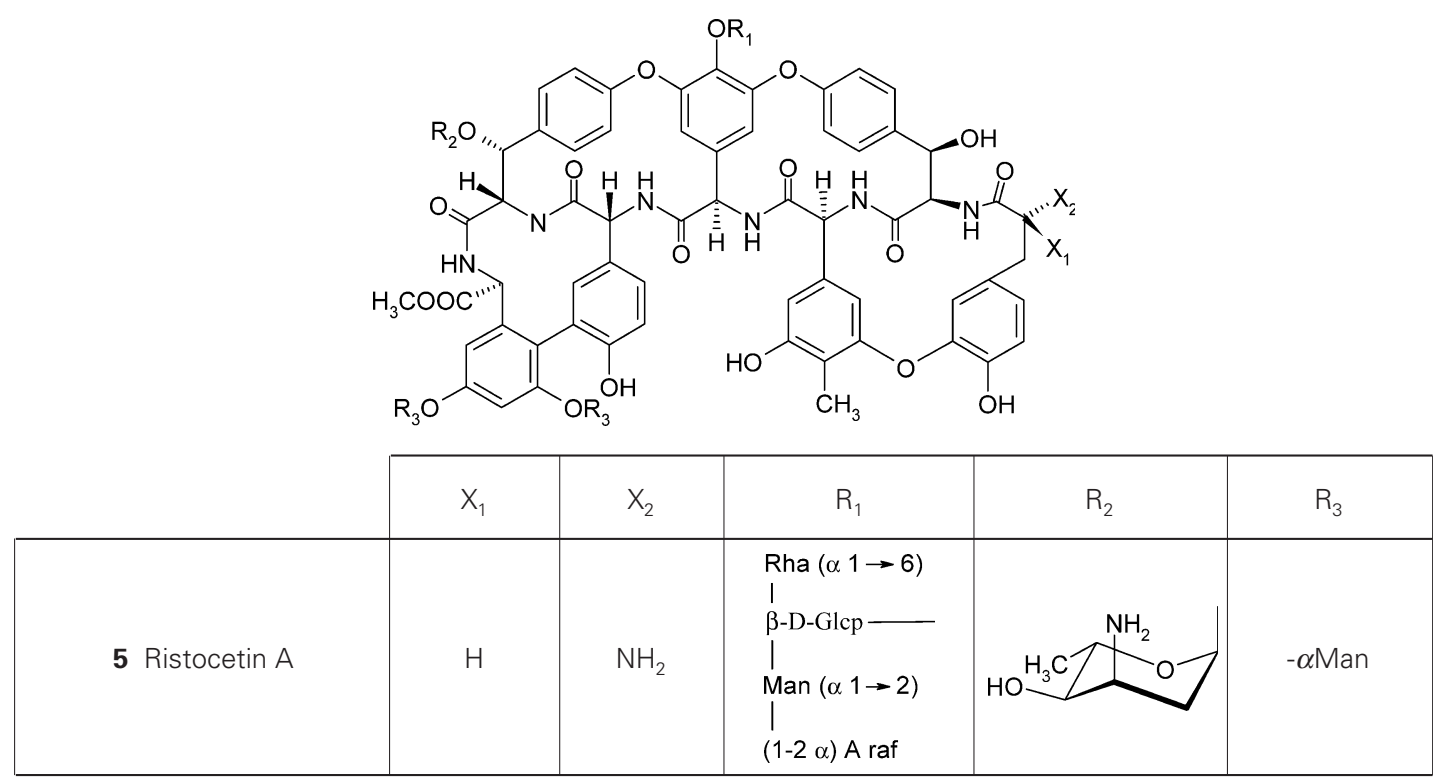

1. HF/anisole, $-18^{\circ} \mathrm{C}, 80 \mathrm{~min}$

2. Column chromatography

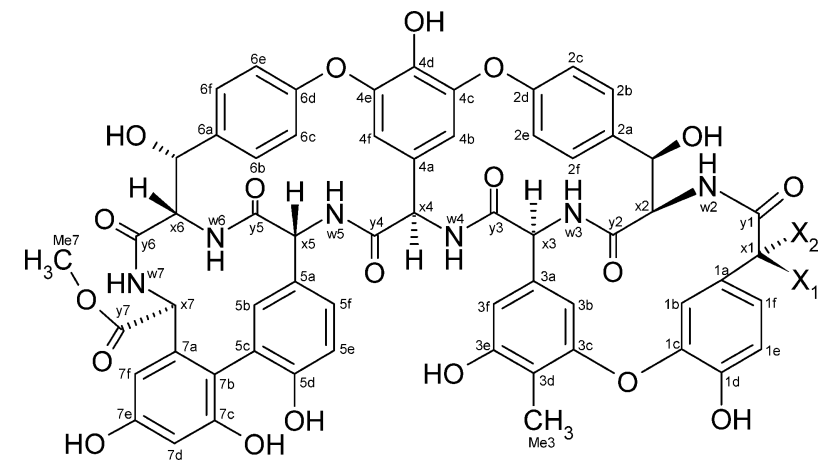

\begin{tabular}{|c|c|c|c|}
\hline \multirow{3}{*}{ Ref. [7] } & & $X_{1}$ & $x_{2}$ \\
\hline & 6 Aglyco-ristocetin & $\mathrm{H}$ & $\mathrm{NH}_{2}$ \\
\hline & 7 Aglyco-epi-ristocetin & $\mathrm{NH}_{2}$ & $\mathrm{H}$ \\
\hline
\end{tabular}

Scheme 2 Deglycosidation of ristocetin A.

respectively.

Scheme 5 shows that the reaction of the $N$-terminal amino group of the aglycone of the glycopeptide antibiotics with dimethyl squarate results first in the reactive squaric acid amide esters, whose treatment with the selected amino compound leads to the target amides. However, such asymmetric molecules can also be constructed (Scheme 5) by the preparation of the reactive vinylamide-type squaric acid half-ester $\mathbf{2 1}$ from dimethyl squarate (7) and triglycine
(20), followed by reaction with the $N$-terminal amino group of 5 or its aglycone $\mathbf{6}$ under basic conditions $(\mathrm{pH}>8)$ to obtain the target molecules 22 and 23. The advantage of both methods is that because of the high regioselectivity no protecting group strategy is needed to perform the experiments.

\section{Mass Spectrometry}

In the reaction of the antibiotics with dimethyl squarate we 


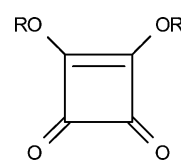

7

$\mathrm{R}=\mathrm{Me}, \mathrm{Et}$
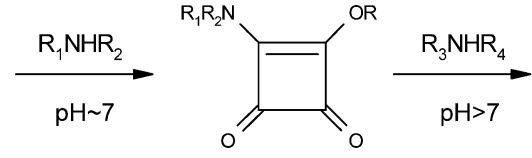

8

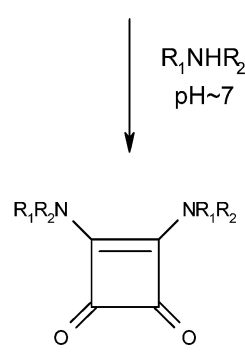

9<smiles>[Y20]c1c(N)c(=O)c1=O</smiles>

10

Scheme 3 The squarate linker method [8].

Table 3 Physico-chemical data of the squaric acid monoamides of glycopeptide antibiotics

\begin{tabular}{|c|c|c|c|c|c|c|c|c|c|}
\hline & \multirow[b]{2}{*}{$\begin{array}{l}\text { Squaric acid } \\
\text { monoamides of }\end{array}$} & \multirow[b]{2}{*}{ Yield \% } & \multirow[b]{2}{*}{$\begin{array}{c}\mathrm{HPLC} \\
\mathrm{R}_{\mathrm{t}}\end{array}$} & \multirow[b]{2}{*}{$\begin{array}{c}\text { TLC } \\
\mathrm{Rf}\end{array}$} & \multicolumn{3}{|c|}{ Molecular weight } & \multirow[b]{2}{*}[\alpha]{$_{D}^{20}$} & \multirow[b]{2}{*}{$\begin{array}{c}\text { UV } \lambda_{\max } \\
\mathrm{nm}\end{array}$} \\
\hline & & & & & $\begin{array}{l}\text { Formula of } \\
\text { compounds }\end{array}$ & Calculated & $\begin{array}{c}\text { Measured } \\
\text { MALDI-TOF } \\
(\mathrm{M}+\mathrm{Na})^{+}\end{array}$ & & \\
\hline 11 & Eremomycin & 53.0 & 1.72 & (1B) 0.31 & $\mathrm{C}_{78} \mathrm{H}_{91} \mathrm{~N}_{10} \mathrm{O}_{29} \mathrm{Cl}$ & 1668.04 & 1689.66 & $\begin{array}{c}-48.42 \\
(c=0.28, \mathrm{DMSO})\end{array}$ & $\begin{array}{c}273 \\
\text { (DMSO) }\end{array}$ \\
\hline 12 & Vancomycin & 35.05 & 8.05 & $\begin{array}{l}(1 \mathrm{~A}) 0.26 \\
(2 \mathrm{C}) 0.64\end{array}$ & $\mathrm{C}_{71} \mathrm{H}_{77} \mathrm{~N}_{9} \mathrm{O}_{27} \mathrm{Cl}_{2}$ & 1559.29 & 1580.58 & $\begin{array}{c}32.08 \\
(c=0.21, \mathrm{DMF})\end{array}$ & $\begin{array}{c}281 \\
\text { (DMF) }\end{array}$ \\
\hline 13 & Ristocetin-A & 82.8 & 4.32 & $(1 \mathrm{~A}) 0.43$ & $\mathrm{C}_{100} \mathrm{H}_{112} \mathrm{~N}_{8} \mathrm{O}_{47}$ & 2177.0 & 2199.33 & $\begin{array}{c}-161.94 \\
(c=0.20, \mathrm{DMF})\end{array}$ & $\begin{array}{c}277 \\
\text { (DMF) }\end{array}$ \\
\hline 14 & Ristocetin-aglycone & 60.10 & 36.51 & (2D) 0.36 & $\mathrm{C}_{65} \mathrm{H}_{53} \mathrm{~N}_{7} \mathrm{O}_{22}$ & 1284.13 & 1306.50 & $\begin{array}{c}-126.99 \\
(c=0.20, \mathrm{MeOH})\end{array}$ & $\begin{array}{c}277 \\
(\mathrm{MeOH})\end{array}$ \\
\hline
\end{tabular}

TLC: (1) DC Cellulose

(2) Kieselgel $60 \mathrm{~F}_{254}$

Detection: Pauly-reagent

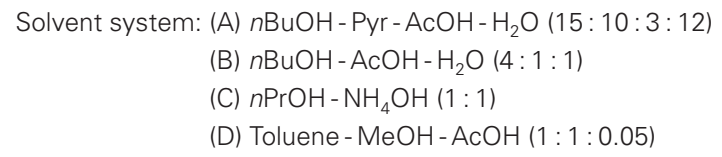

(C) $n \mathrm{PrOH}-\mathrm{NH}_{4} \mathrm{OH}(1: 1)$

(D) Toluene- $\mathrm{MeOH}-\mathrm{AcOH}(1: 1: 0.05)$

observed the formation of a single product, the site of the attachment was unknown. Theoretically, from eremomycin three types of monosquaramide can be obtained, from vancomycin and ristocetin A two possible regioisomers can be deduced. We solved this problem using electrospray mass spectrometry.

A preliminary experiment was done on the protonated molecular ion of $\mathbf{1 9}$ to see the tandem mass spectrometric behavior of the squaric acid-modified aglycone. The loss of the squaric acid moiety was found to be the most characteristic process. In the eremomycin derivative $\mathbf{1 6}$ there are three possible places to which the squaric acid may be bond: the two amino sugar moieties and the $\mathrm{N}$ terminus of the peptide core. The molecular weight of $\mathbf{1 6}$ (1819.2) is out of the mass range of the instrument so the doubly charged ion at $m / z=910.3$ was selected as precursor in the EPI experiment. Singly and doubly charged ions are also appeared in the spectrum. The most intense peak in the spectrum at $m / z=1676.3$ is formed by loss of $144 \mathrm{Da}$. The mass of both $R_{2}$ and $R_{3}$ (for abbreviations see Scheme 1 and 2) is 144 but the consecutive loss of $305 \mathrm{Da}$ resulting a peak at $m / z=1371.1$ clearly shows that the former is due to 


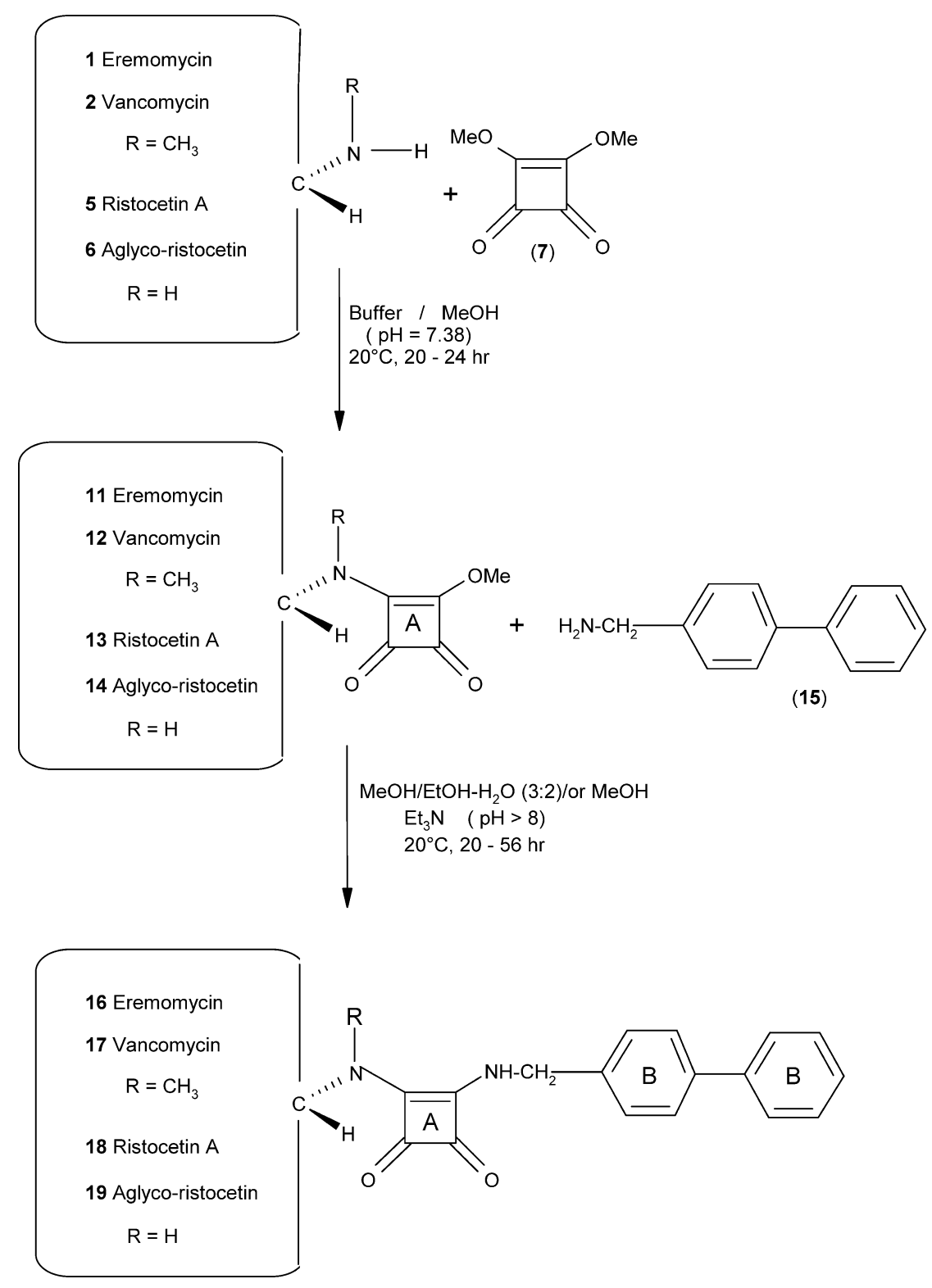

Scheme 4 Preparation of the squaric acid amide esters and asymmetric diamides.

the loss of $\mathrm{R}_{3}$ and the latter is that of the disaccharide chain containing $\mathbf{R}_{2}$, respectively. Peaks in the lower $m / z$ region at 144 and 306 are correspondent to the $R_{1}$ and to the disaccharide unit with $\mathrm{R}_{2}$, respectively. No peaks could be found in the spectrum corresponding to the combination of either of the two aminosugars and the squaric acid (Figure 2 ). From these data it can be concluded that the squaric acid was bonded to the $N$-terminus of the peptide chain.

There are only two possible positions for the reaction with squaric acid in vancomycin, i.e. the $\mathrm{R}_{2}$ and the $N$ terminus. The EPI experiment with derivative $\mathbf{1 7}$ was done on the doubly charged molecule (856.3). The spectrum obtained is quite simple, only several peaks appeared.
The most intense peak at $m / z=1406.2$ is attributed to corresponding to the loss of the disaccharide unit with $\mathrm{R}_{2}$. This is only possible if the squaric acid is linked at the $\mathrm{N}$-terminus in the molecule (Figure 3).

The EPI spectrum of the doubly charged ristocetin derivative 18 seemed the most complicated among the spectra of antibiotics examined, and this is due to the number and complexity of the carbohydrate side chains. There are two possible positions of the squaric acid: at the aminosugar $\left(\mathrm{R}_{2}\right)$ and at the $\mathrm{X}_{2}$. The combination of the consecutive losses of $R_{1} R_{2} R_{3}$ and $167 \mathrm{Da}$ (biphenylmethyl group from the squaric acid part) can be found in the spectrum (Figure 4). There are two peaks in the spectrum at 


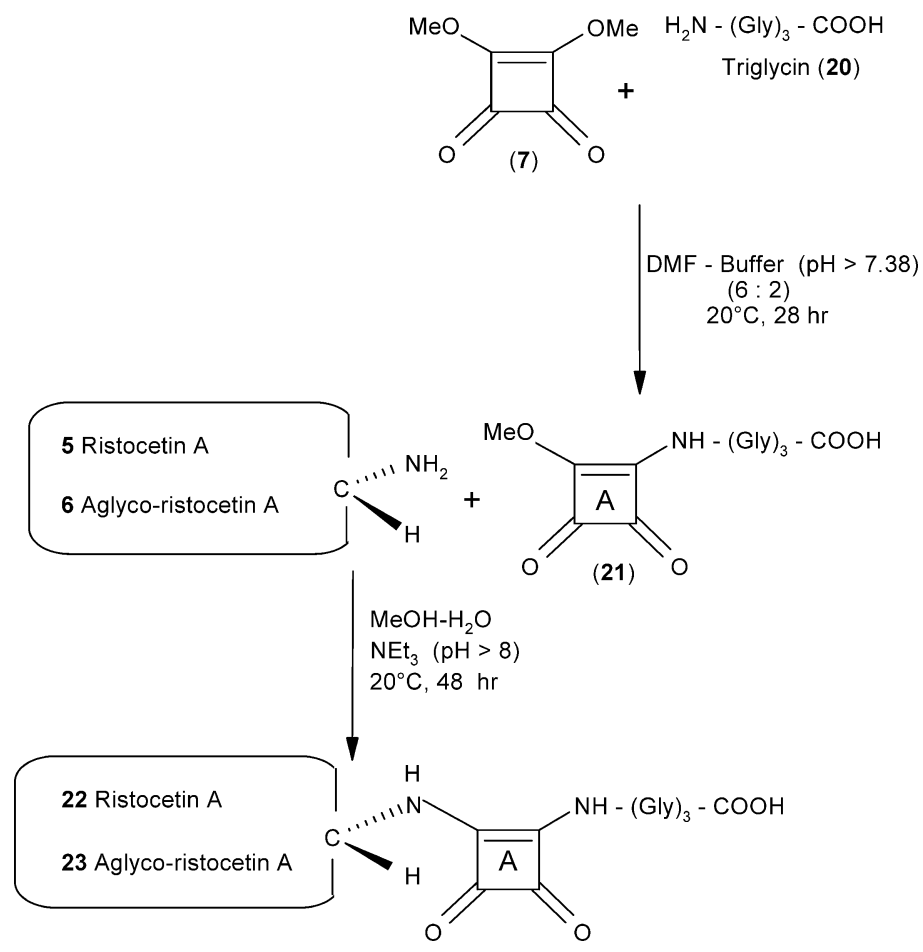

Scheme 5 Synthesis of the squaric acid asymmetric diamides of triglycine and ristocetin-A or aglyco-ristocetin-A.

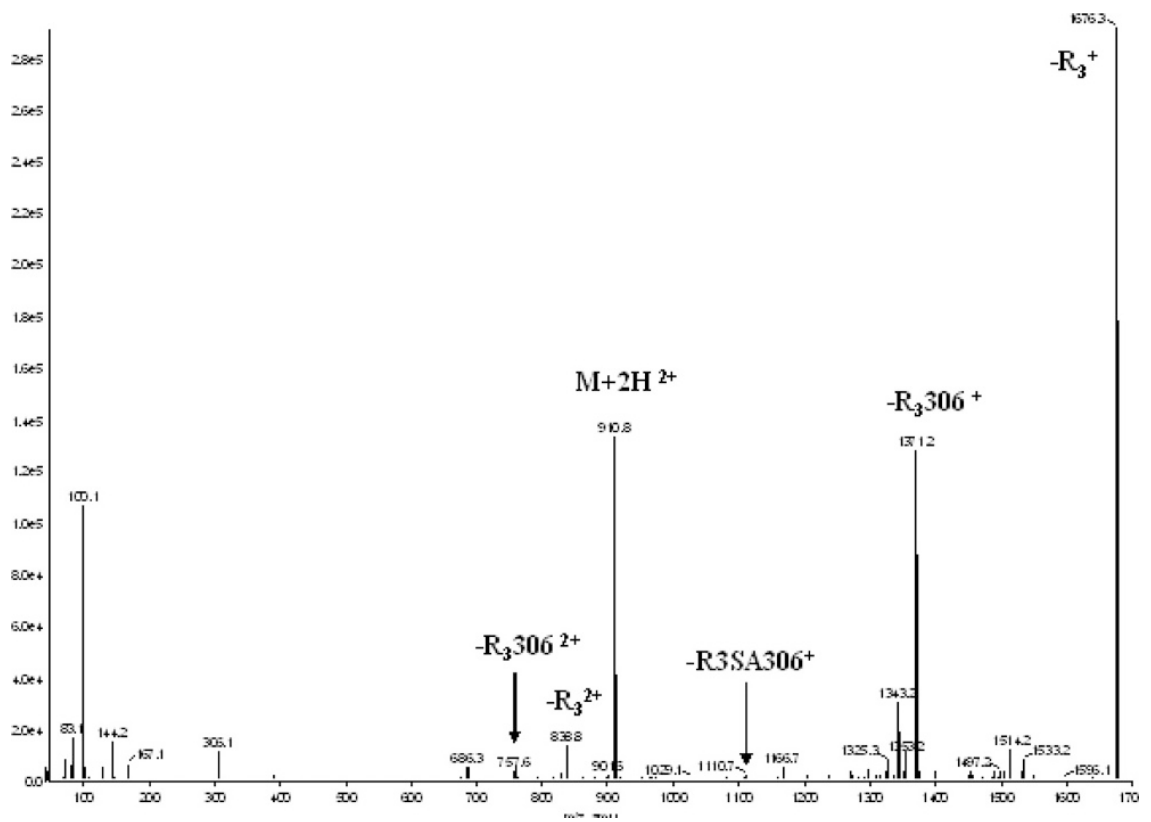

Fig. 2 Enhanced product ion (EPI) spectrum of the doubly charged eremomycin derivative (16).

SA represents the squaric acid moiety.

$m / z=1598.2$ and 1436.2 , corresponding to the loss of $\mathrm{R}_{1}+\mathrm{R}_{2}$ and $\mathrm{R}_{1}+\mathrm{R}_{2}+\mathrm{R}_{3}$, respectively, containing the squaric acid moiety but not an aminosugar portion. The latter has the same mass as the protonated molecular ion of the aglyco-ristocetin A derivative 19. These data support our assumption that the sqaric acid is connected to the antibiotic at position $\mathrm{X}_{2}$. 


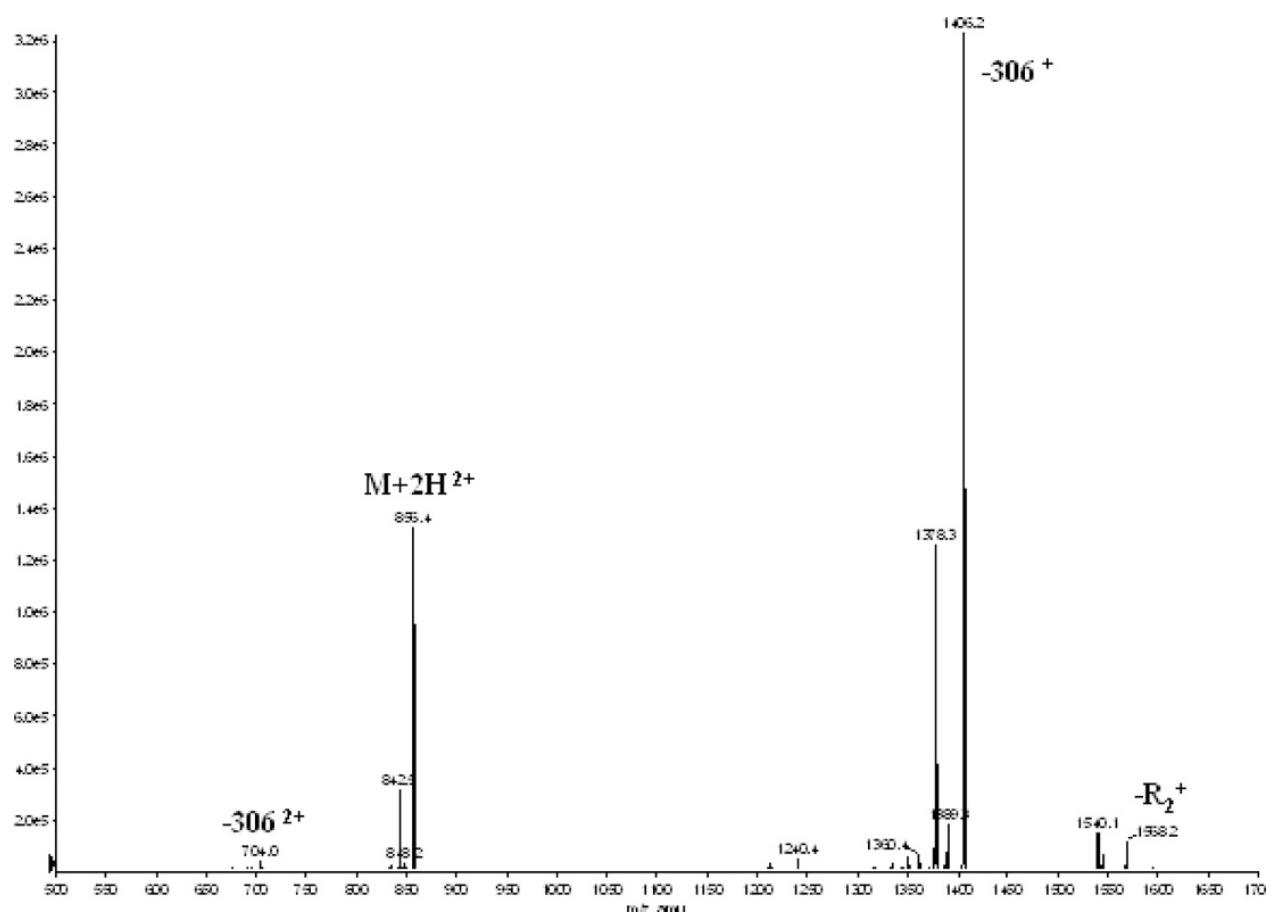

Fig. 3 Enhanced product ion (EPI) spectrum of the doubly charged vancomycin derivative (17).

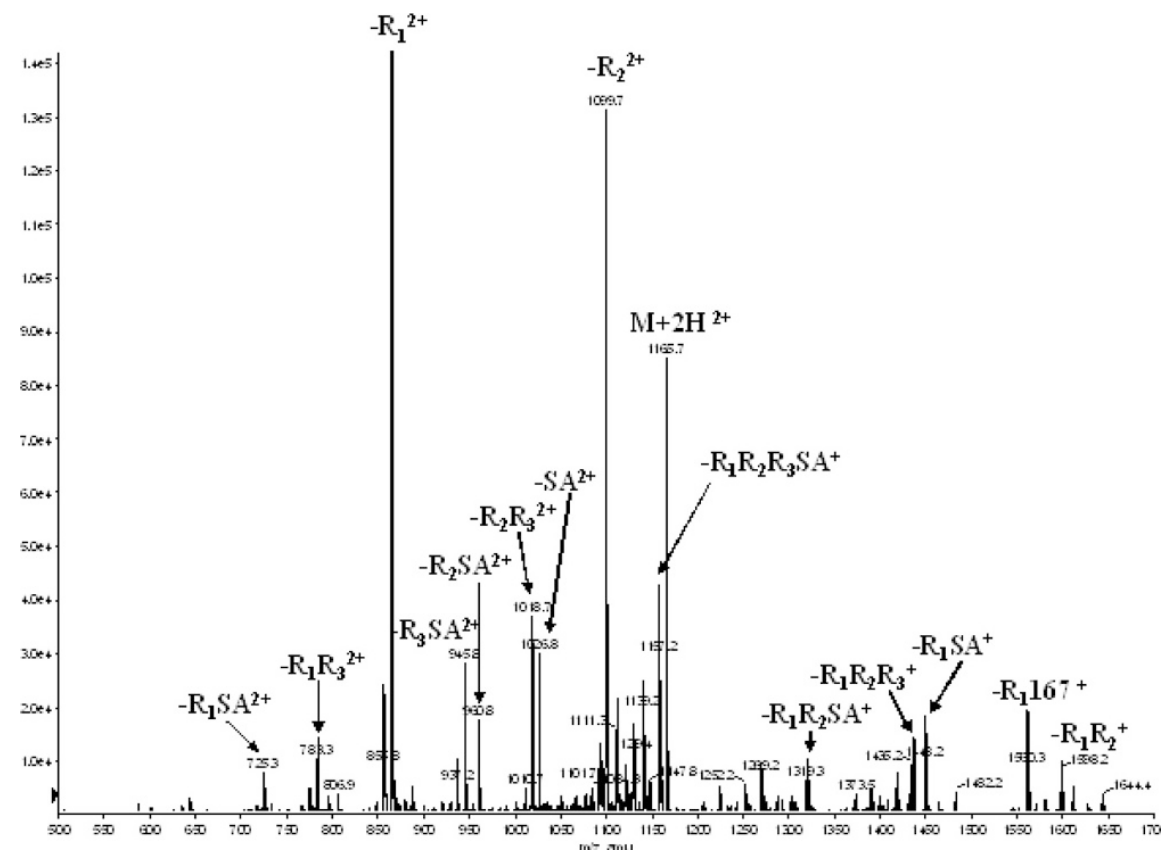

Fig. 4 Enhanced product ion (EPI) spectrum of the doubly charged ristocetin-A derivative (18).

SA represents the squaric acid moiety.

Concerted ${ }^{1} \mathrm{H},{ }^{13} \mathrm{C}$ and ${ }^{15} \mathrm{~N}$ NMR Assignment of the Four Basic Glycopeptide Aglycones and Application in the Structure Elucidation of New Derivatives

Structures of antibiotics are often supported by detailed ${ }^{1} \mathrm{H}-$
${ }^{13} \mathrm{C}$ NMR analysis, however ${ }^{15} \mathrm{~N}$ data are sparse (missing for aglycones). It has been demonstrated that ${ }^{15} \mathrm{~N}$ chemical shifts are extremely useful for locating $\mathrm{H}$-bonds [17, 18] while ${ }^{15} \mathrm{~N}$ relaxation gives more insight into dynamics [19]. 

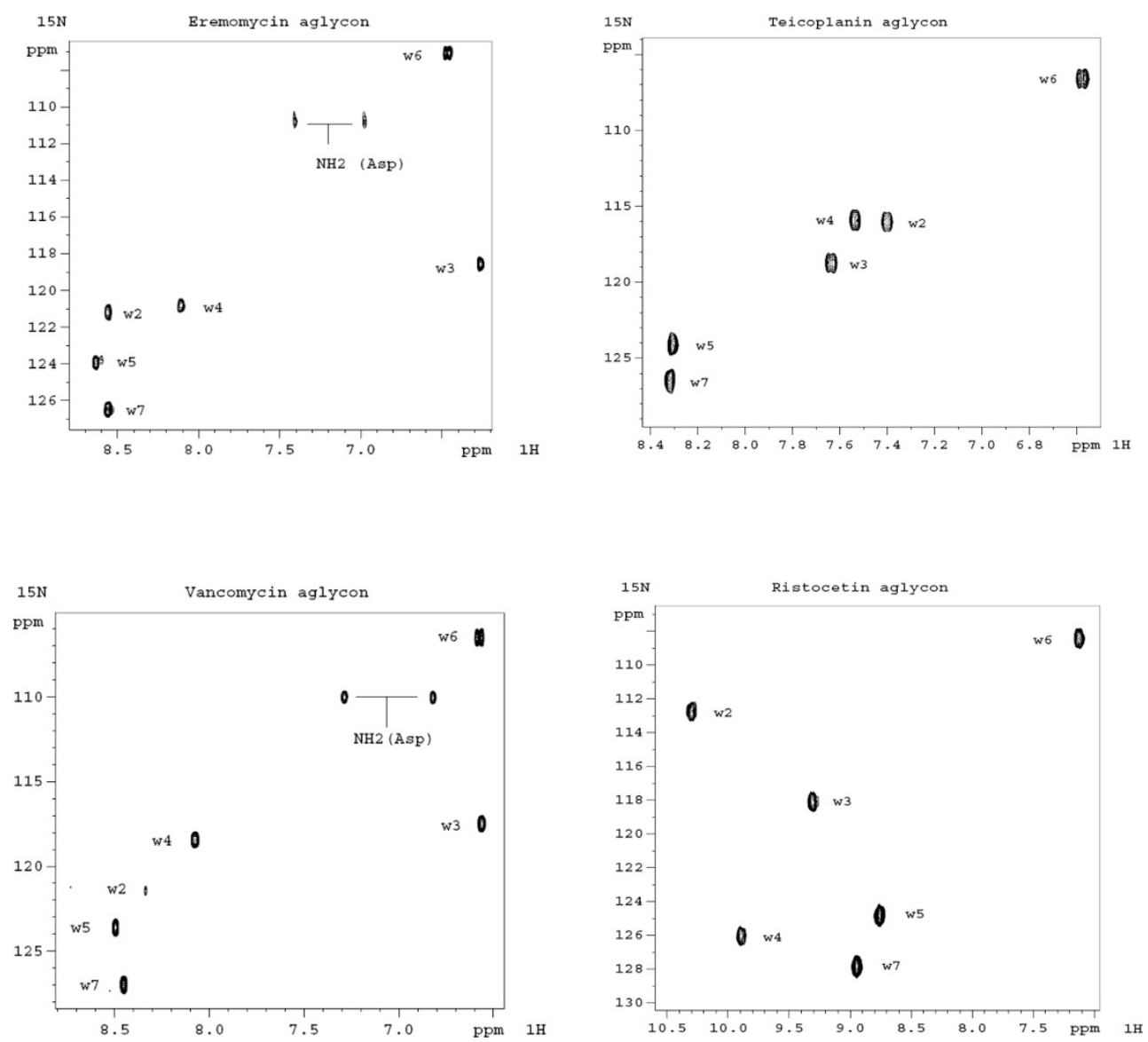

Fig. 5 Comparison of the ${ }^{15} \mathrm{~N} /{ }^{1} \mathrm{H}$ HSQC spectra of the four aglycones.

Pioneer NMR assignments are difficult to compare, since the experimental conditions and methods are very different. In aqueous solution, many glycopeptide antibiotics form asymmetric dimers, and therefore experiments were often carried out in DMSO solution, at high temperature to get rid of exchange broadened peaks. Certain derivatives, including the aglycones, are poorly soluble in water. Early aglycone assignments were mostly based on chemical shift comparison and homonuclear correlations; e.g. for teicoplanin [20] and vancomycin [21, 22], eremomycin [23].

The assignment strategy for the aglycones was similar to our earlier methods, however in this work the starting points were the amides that were identified from the ${ }^{15} \mathrm{~N}$ HSQC-spectra (Figure 5). The main chain ${ }^{1} \mathrm{H}$ assignment of the heptapeptide core was augmented with homonuclear NOESY in addition to COSY and TOCSY spectra. Sequential NH-NH NOE-s can be observed at the $N$ terminus up to residue 4 , because of the $\beta$-sheet like secondary structure [24]. Due to limited homonuclear connectivites ${ }^{13} \mathrm{C}$ assignments were based on ${ }^{13} \mathrm{C}-{ }^{1} \mathrm{H}$ HSQC and $\mathrm{HMBC}$ spectra for detecting one-bond and long-range heteronuclear connectivities. The latter was especially useful for the assignments of the aromatic rings. The NMR assignments of the four aglycones are grouped in tables (Table 2a, 2b Table 2c, 2d) containing the vancomycineremomycin and ristocetin-teicoplanin pairs. It can be seen that the independent (self-consistent) full assignments of the pairs are well comparable, lending further support to their reliability. Furthermore, comparison with earlier assignments of the intact eremomycin and its aglycone [23] supports that the aglycone does not form dimers in DMSO solution, in contrast to eremomycin in aqueous solution. This is proved by the ${ }^{1} \mathrm{H}$ chemical shift of the 6e proton $(\delta=6.89 \mathrm{ppm})$ in the monomeric aglycone, in contrast to $5.3 \mathrm{ppm}$ in the dimer, where the unusual aromatic shift is due to orthogonal $\sigma-\pi$ interaction between H-6e and ring 4. ACD chemical-shift prediction software [25] proved to be useful: though it was insufficient for predicting small chemical shift differences. Because of better solubility and resolution we gave the assignments of the ristocetin aglycone in methanol solution.

\section{Squaric Acid Derivatives of the Glycopeptide Aglycones}

In Table 5 we present only the assignments of the 
substituents attached the glycopeptide aglycones. The presence of the aglycones was proved by overlaying their 2D-HSQC spectra with the appropriate aglycone, although it is occasionally complicated with signal-doubling due to the presence of the amide group restricted rotation in the squaric acid [8]. Therefore, some assignments are missing (see as ND label) due to low signal — to noise ratio in their ${ }^{13} \mathrm{C}$ NMR spectra. However, in such cases, mass spectra were convincing about the identity of the semisynthetic derivatives and the site of the squaric acid attachment.

\section{Antibacterial Activity}

The aglycones are responsible for the biological activity of

Table 4 Squaric acid asymmetric diamides of glycopeptide antibiotics

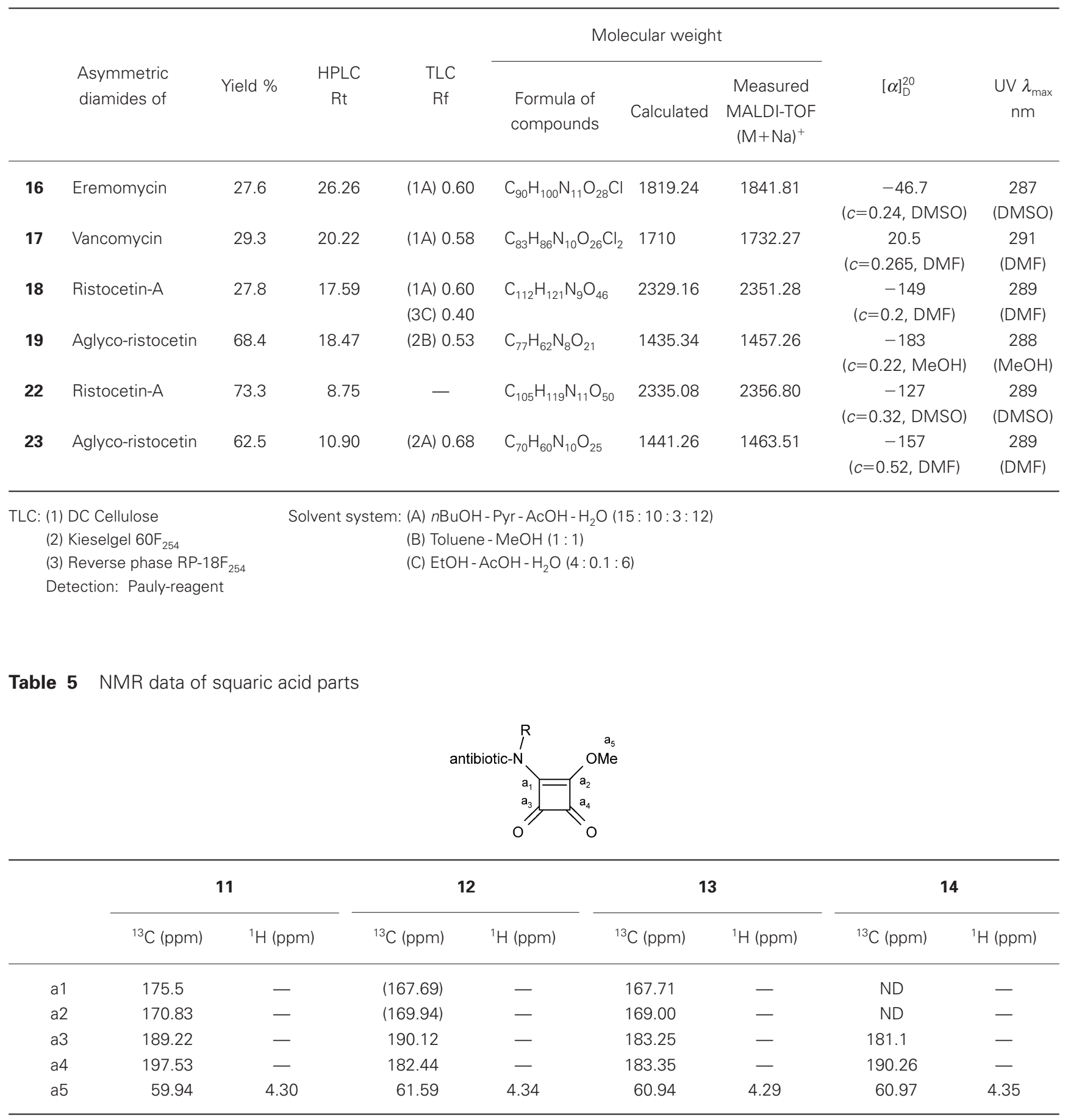


Table 5 (continued)

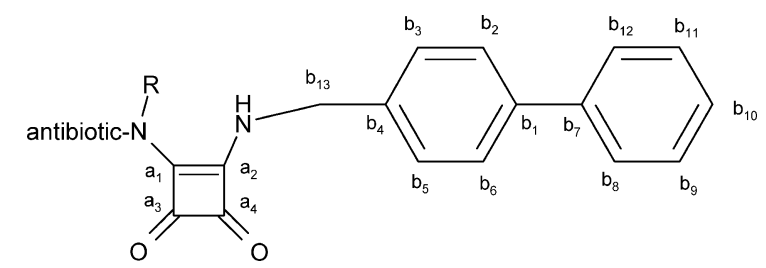

\begin{tabular}{|c|c|c|c|c|c|c|}
\hline & \multicolumn{2}{|c|}{17} & \multicolumn{2}{|c|}{18} & \multicolumn{2}{|c|}{19} \\
\hline & ${ }^{13} \mathrm{C}$ (ppm) & ${ }^{1} \mathrm{H}$ (ppm) & ${ }^{13} \mathrm{C}$ (ppm) & ${ }^{1} \mathrm{H}$ (ppm) & ${ }^{13} \mathrm{C}$ (ppm) & ${ }^{1} \mathrm{H}$ (ppm) \\
\hline a1 & 167.82 & - & 167.19 & - & 169.13 & - \\
\hline a2 & 168.66 & - & 168.8 & - & 168.91 & - \\
\hline a3 & 183.39 & - & 183.66 & - & 183.53 & - \\
\hline a4 & 182.94 & - & ND & - & 183.27 & - \\
\hline b1 & 140.05 & - & 140.4 & - & 140.26 & - \\
\hline b2. b6 & 127.70 & 7.65 & 127.7 & 7.65 & 127.50 & 7.65 \\
\hline b3. b5 & 129.13 & 7.51 & 129.6 & 7.45 & 129.70 & 7.45 \\
\hline b4 & 139.22 & ND & 138.72 & - & 139.47 & - \\
\hline b7 & 140.70 & ND & 140.77 & - & 140.68 & - \\
\hline b8. b12 & 127.70 & 7.65 & 127.7 & 7.65 & 127.40 & 7.61 \\
\hline b9. b11 & 129.13 & 7.41 & 129.00 & 7.41 & 129.00 & 7.40 \\
\hline b10 & 128.29 & 7.37 & 128.40 & 7.36 & 128.20 & 7.35 \\
\hline b13 & 47.21 & 4.83 & 47.54 & 4.77 & 47.37 & 4.77 \\
\hline
\end{tabular}<smiles></smiles>

22

23

${ }^{13} \mathrm{C}(\mathrm{ppm}) \quad{ }^{1} \mathrm{H}(\mathrm{ppm}) \quad{ }^{13} \mathrm{C}(\mathrm{ppm}) \quad{ }^{1} \mathrm{H}$ (ppm)

$\begin{array}{lccrc}\text { a1 } & 168.94 & - & 167.35 & - \\ \text { a2 } & \text { ND } & - & 168.50 & - \\ \text { a3 } & 183.86 & - & 184.01 & - \\ \text { a4 } & \text { ND } & - & 183.70 & 3.44 \\ \text { c1 } & 43.53 & 3.54 & 43.83 & 3.76 \\ \text { c2 } & 43.18 & 3.77 & 43.29 & 4.29 \\ \text { c3 } & 46.82 & 4.28 & 46.71 & -\end{array}$

ND are not detectable signals because of low signal-to noise ratio. The characteristic ${ }^{13} \mathrm{C}$ and ${ }^{1} \mathrm{H}$ NMR signals of the glycopeptide antibiotic parts of the molecules are not listed, though they were unambiguously detected in the overlayed 2D HSOC spectra according to the assigned spectra of the aglycones. 
Table 6 Antibacterial activity of the glycopeptide antibiotics and their derivatives

\begin{tabular}{|c|c|c|c|c|c|c|c|c|c|c|c|c|c|c|c|c|c|}
\hline \multirow{3}{*}{ Test microorganism } & \multicolumn{17}{|c|}{$\operatorname{MIC}(\mu \mathrm{g} / \mathrm{ml})$} \\
\hline & \multicolumn{4}{|c|}{ Eremomycin } & \multicolumn{4}{|c|}{ Vancomycin } & \multicolumn{8}{|c|}{ Ristocetin } & \multirow{2}{*}{$\begin{array}{l}\text { Linezolid } \\
\text { [30] }\end{array}$} \\
\hline & 1 & 3 & 11 & 16 & 2 & 4 & 12 & 17 & 5 & 6 & 13 & 14 & 18 & 19 & 22 & 23 & \\
\hline Bacillus subtilis ACTC 6633 & $<0.5$ & 32 & 1 & 1 & $<0.5$ & 1 & 2 & 0.5 & $<0.5$ & 2 & 8 & 16 & 0.5 & 2 & 8 & 8 & 1.0 \\
\hline Staphylococcus aureus ACTC 29213 (MSSA) & 0.5 & 32 & 2 & 8 & 2 & 4 & 4 & 1 & 1 & 2 & 64 & 8 & 4 & 1 & 128 & 4 & 2.0 \\
\hline S. aureus ACTC 33591 (MRSA) & 0.5 & 32 & 4 & 16 & 2 & 4 & 8 & 2 & 4 & 2 & 128 & 8 & 16 & 8 & 128 & 4 & 1.5 \\
\hline S. epidermidis ACTC 25299 (MSSE) & 0.5 & 8 & 2 & 2 & 2 & 4 & 2 & 2 & 2 & 2 & 64 & 4 & 32 & 0.5 & 32 & 8 & 1.0 \\
\hline S. epidermidis IMMSU 12333/05 (MRSE) & 2 & 128 & 8 & 64 & 4 & 4 & 4 & 8 & 16 & 4 & 128 & 32 & 32 & 8 & 128 & 32 & 1.0 \\
\hline Enterococcus faecalis ACTC 29212 (VSEF) & 1 & 64 & 8 & 4 & 2 & 4 & 16 & 1 & 2 & 4 & 32 & 16 & 1 & 1 & 1 & 4 & 4.0 \\
\hline E. faecalis ACTC 51299 (GREF) & 8 & $>256$ & 64 & 16 & 32 & 8 & 32 & 16 & 8 & 16 & 128 & 64 & 2 & 8 & 4 & 4 & 3.0 \\
\hline
\end{tabular}

ACTC: American Collection of Typed Culture, MSSA: Methicillin sensitive S. aureus, MRSA: Methicillin resistant S. aureus, VSEF: Vancomycin (and teicoplanin) sensitive E. faecalis, GREF: Glycopeptide resistant E. faecalis, MRSE: Methicillin resistant S. epidermidis, MSSE: Methicillin sensitive S. epidermidis.

the glycopeptide antibiotics. The antimicrobial activities of the aglycones, obtained after removal of the carbohydrate moieties, in comparison with those of the parent antibiotics are summarized in Table 6.

Deglycosydation of eremomycin (1) to 3 results in a surprising decrease in the activity against all of the tested seven microorganisms. The activity of aglyco-vancomycin (4) against Bacillus subtilis decreased to more than the half of the original value, and $c a$. to the half against methicillinsensitive and resistant Staphylococcus aureus (MSSA, MRSA) and S. epidermidis (MRSE, MSSE).

According to Boger [26], the elemental composition and structural features of the aglycones $\mathbf{3}$ and $\mathbf{4}$ are very similar, and-besides the atropisomerism (rings 5 and 7) of actinoidinic acid - the chloro substituent of the aromatic rings of $\mathbf{2}$ and $\mathbf{6}$ has a complementary role in the affinity and selectivity of binding to the L-Lys-D-Ala-D-Ala tripeptide of the bacterial cell wall. By comparing the antibiotic activity of $\mathbf{1}$ and $\mathbf{3}$ and $\mathbf{6}$, Russian researchers came to the same conclusion $[14,15]$.

In the case of ristomycin A (5), the aglyco-ristomycin (6), which does not carry a covalent chloro atom, a positive change in the activity against both MSSA and MRSA was observed. This aglycone (6) was found twice as active against MRSA as the parent antibiotic (5). As compared to 5, the activity of $\mathbf{6}$ against both Enterococcus faecalis strains dropped to half, and to one-fourth against $B$. subtilis. The MIC values for $\mathbf{6}$ and $\mathbf{2}$ are approximately the same obtained with the organisms $S$. aureus, $S$. epidermidis and E. faecalis. Moreover, these efficacies compare favourably [30] to those of the new synthetic oxazolidinone derivative, linezolid which is in clinical use.
The antibacterial activity of the of the squaric acid amide esters $\mathbf{1 1}$ and 13, derived from eremomycin and ristocetin A, against the test microorganisms is much decreased as compared to both of the parent antibiotics $\mathbf{1}$ and $\mathbf{5}$, and to the corresponding aglycones. At the same time, the squaric acid amide ester of aglyco-ristocetin (14) possesses lower decrease in activity than compound $\mathbf{1 3}$.

Of the asymmetric squaric amides 18 and 19, derived from ristocetin A (5) and aglyco-ristocetin A (6), respectively, with 4-phenylbenzylamine (15), the activity of 18 significantly increased against $B$. subtilis and $E$. faecalis (VSEF, GREF).

Except for MRSA, the effectiveness of $\mathbf{1 9}$ is higher than that of $\mathbf{1 4}$ towards each of the investigated bacterial strains, and practically identical with that of the starting aglycone 6.

\section{Experimental}

The samples of eremomycin, ristocetin A and aglycoteicoplanin were received from the Gauze Institute of New Antibiotics (Moscow). Vancomycin hydrochloride was purchased from Aldrich Co.

The solutions were evaporated under diminished pressure at $40^{\circ} \mathrm{C}$. Preparative column chromatography was performed on Silica gel $60(0.063 \sim 0.2 \mathrm{~mm}$, Merck $)$ and Silica gel 60 silanized $(0.063 \sim 0.2 \mathrm{~mm}$, Merck) adsorbents. HPLC was carried out with a Waters 600 instrument using UV detection at $230 \mathrm{~nm}$. Column: Lichrospher RP-8 $(4 \times 250 \mathrm{~mm} 10 \mu \mathrm{m})$; injection volume: $20 \mu \mathrm{l}$ (from $0.1 \mathrm{mg} / \mathrm{ml})$. Eluent A: $\mathrm{CF}_{3} \mathrm{COOH}-\mathrm{H}_{2} \mathrm{O}(\mathrm{pH}=2.65)$; $\mathrm{B}$ : 
$\mathrm{MeCN}$ - water, gradient elution from $10 \%$ to $90 \%$. The UV spectra were recorded with a Perkin-Elmer Lambda 11 instrument. The specific optical rotation values were measured with a Perkin-Elmer 341 automatic polarimeter. MALDI-TOF MS spectra were obtained with a Bruker BIFLE X III spectrometer. Positive ions were detected in the reflektron mode. Samples were prepared with DBH matrix dissolved in DMSO $(20 \mathrm{mg} / \mathrm{ml})$. Concentrations of compounds: $5 \mathrm{mg} / \mathrm{ml}$. An Applied Biosystems 3200 Qtrap hybrid linear ion trap mass spectrometer equipped with TurboV ion source was used for the identification of the position of the squaric acid moiety. The samples were dissolved in acetonitrile : water : formic acid $50: 50: 0.1 \%$ solution and were infused using a built-in syringe pump with a flow rate of $10 \mu \mathrm{l} /$ minute. The ionization potential was $5000 \mathrm{~V}$. The instrument was scanned in linear ion trap (LIT) mode using a scan range of 500 1700 and 50 1700 in enhanced MS (EMS) and enhanced product ion (EPI) experiments, respectively. The Q0 trapping function was turned on. NMR samples were measured in DMSO- $d_{6}$ solution at 330 or $340 \mathrm{~K}$, except the aglyco-ristocetin $\left(\mathrm{MeOH}-d_{4}\right.$ or $\mathrm{MeOH} / \mathrm{MeOH}-d_{4}$ 9:1 mixture for ${ }^{15} \mathrm{~N}$, $300 \mathrm{~K})$. Chemical shifts are referenced to published residual solvent signals (39.51 for DMSO- $d_{6}$ and 49.15 $\mathrm{MeOH}-d_{4}$ for ${ }^{13} \mathrm{C}$ or $\mathrm{TMS}=0$ for ${ }^{1} \mathrm{H}$ NMR). A Bruker DRX-500 spectrometer equipped with a $5 \mathrm{~mm}$ inverse broadband gradient probe head (with 10, 13 and $23 \mu \mathrm{s}$ duration of $90^{\circ}$ pulses for ${ }^{1} \mathrm{H},{ }^{13} \mathrm{C}$ and ${ }^{15} \mathrm{~N}$ channels) was used. Simple, gradient-enhanced magnitude representation COSY-60 spectra were run with solvent presaturation when necessary. Gradient and sensitivity enhanced TOCSY spectra were acquired with DIPSI2 mixing sequence of $60 \mathrm{~ms} .{ }^{13} \mathrm{C}-{ }^{1} \mathrm{H}$ and ${ }^{15} \mathrm{~N}-{ }^{1} \mathrm{H}$ HSQC spectra were obtained with gradient and sensitivity enhancement $\left({ }^{15} \mathrm{~N}\right.$ spectra required overnight accumulation at natural abundance). The used NOESY pulse sequence was equipped with the Hahn spin-echo to remove broad solvent lines and baseline bias. The same spin-echo technique was applied in $1 \mathrm{D}{ }^{1} \mathrm{H}$ signal accumulation. In case of derivatives, straight ${ }^{13} \mathrm{C}$ accumulation was sometimes a bottleneck, because of the low ${ }^{13} \mathrm{C}$ sensitivity of the inverse probe. Therefore, in such cases, the basic acquisition scheme of $30^{\circ}{ }^{13} \mathrm{C}$ read pulse was applied, instead of the more informative J-modulated spin-echo sequence. The gradient enhanced HMBC sequence was preceded with a filter to suppress one-bond correlations and ${ }^{13} \mathrm{C}$ decoupling was applied during acquisition. SPARKY software package [31] was used for visualization and assignment.

For the deglycosidation experiments a Toho Kasei (Japan) apparatus at the Department of Organic Chemistry, Lóránd Eötvös University of Budapest was used.

\section{Deglycosidation of Eremomycin and Vancomycin}

Deglycosidation of eremomycin and vancomycin was carried out as described earlier by Wanner et al. [5] $\left(25^{\circ} \mathrm{C}\right.$, 2 hours). The physico-chemical data of the prepared aglycones $\mathbf{3}$ and $\mathbf{4}$ are collected in Table 1, and the NMR data are presented in Tables $2 a \sim b$.

\section{Preparation of Aglyco-ristocetin A (6)}

In the teflon tube of the deglycosidation instrument anisole $(1.9 \mathrm{ml})$ was added to ristocetin A sulfate $(5200 \mathrm{mg})$, the mixture was cooled to -70 to $-80^{\circ} \mathrm{C}$ and $50 \mathrm{ml}$ of $\mathrm{HF}$ was added. The excess of HF was then removed through a $\mathrm{CaO}$ trap in vacuum at $-18^{\circ} \mathrm{C}$. The crude reaction product was washed three times with an ice-cold $4: 1$ ethyl acetate methanol mixture, filtered and dried in a vacuum desiccator. The product contained three UV-detectable components on TLC.

\section{Column Chromatography}

The crude aglycone was dissolved in methanol, containing a small amount of acetic acid $(6 \mathrm{ml}$ methanol +2 drops of $\mathrm{AcOH}$ ), and it was applied onto the surface of Silicagel 60 $(3.0 \mathrm{~g})$ by evaporation. The residue was applied to the top of a Silicagel $60(0.063 \sim 0.2 \mathrm{~mm})$ column $(50 \times 2 \mathrm{~cm})$, and gradient elution was performed with toluene- $\mathrm{MeOH}$ $\mathrm{AcOH}(7: 3: 0.1) \rightarrow$ toluene $-\mathrm{MeOH}-\mathrm{AcOH}(6: 4: 0.1)$. The fractions with Rf: 0.26 was collected, evaporated and dried in a vacuum desiccator to furnish $1.50 \mathrm{~g}(52.8 \%)$ of $\mathbf{6}$, whose physical and NMR data are shown in Tables 1 and $2 \mathrm{c} \sim \mathrm{d}$, respectively.

\section{Synthesis of the Squaric Acid Amide Esters 11 14 of the Glycopeptide Antibiotics and Their Aglycones}

To a solution of the antibiotic/aglycone $\mathbf{1} \sim \mathbf{6}(0.1 \mathrm{mmol})$ in Tristisol buffer $(5.0 \mathrm{ml}, \mathrm{pH}=7.3)$ dimethyl squarate $(7,0.1 \mathrm{mmol})$ was added at room temperature, and the mixture was stirred at the same temperature overnight. The resulting precipitate was filtered off, and washed three times with distilled water $(3.0 \mathrm{ml})$, methanol and ether $(3.0 \sim 3.0 \mathrm{ml})$. Column chromatographic purification $(6: 4: 0.0 .25$ toluene- $\mathrm{MeOH}-\mathrm{AcOH})$ was necessary only in the case of 14. The yields and the physico-chemical data for the products 11 14 are shown in Table 3, and the NMR characteristics are collected in Table 5 .

\section{Preparation of the Asymmetric Squaric Acid Amides $(16 \sim 19,22,23)$ of the Glycopeptide Antibiotics and Their Aglycones}

Method A

The squaric acid amide esters $\mathbf{1 1} \mathbf{1 4}(0.1 \mathrm{mmol})$ were 
dissolved in a mixture $(\mathrm{pH}>8)$ of water $(4.0 \mathrm{ml})$, methanol $(4.0 \mathrm{ml})$ and triethyl amine $(0.01 \mathrm{ml})$, and then 4-phenylbenzylamine $(\mathbf{1 5}, 0.1 \mathrm{mmol})$ was added. The reaction mixture was stirred overnight, and concentrated under diminished pressure. The residue was washed with methanol and water $(3.0 \sim 3.0 \mathrm{ml})$ and dried in a vacuum desiccator over $\mathrm{CaCl}_{2}$. Compounds 18 and 19 were purified by means of column chromatography. The amide $\mathbf{1 8}$ was chromatographed on silanized Silicagel 60 with gradient elution $\left(8: 2: 0.1 \rightarrow 7: 3: 0.1 \rightarrow 6: 4: 0.15 \quad \mathrm{H}_{2} \mathrm{O}-\mathrm{EtOH}-\right.$ $\mathrm{AcOH})$. Pure 19 was eluted from a Silicagel 60 column with $1: 1$ toluene-methanol. The yields and physicochemical characteristics and NMR data of the prepared 16 19 are presented in Tables 4 and 5, respectively.

\section{Method B. The Reverse Method}

Dimethyl squarate $(\mathbf{7}, 0.5 \mathrm{mmol})$ and triglycine (20, $0.5 \mathrm{mmol}$ ) were dissolved in a mixture of $N, N$-dimethyl formamide $(6.0 \mathrm{ml})$ and Tristisol buffer $(2.0 \mathrm{ml}, \mathrm{pH}>7)$, and the mixture was stirred at room temperature for 28 hours. Evaporation of the reaction mixture under diminished pressure afforded the squaric acid triglycine amide 21, which was purified by column chromatography (eluent: $4: 1: 1 n \mathrm{BuOH}-\mathrm{AcOH}-\mathrm{H}_{2} \mathrm{O}, \mathrm{Rf}=0.46$ ). Compound 5 or $6(0.5 \mathrm{mmol})$ was dissolved in a mixture of Tristisol buffer $(20 \mathrm{ml})$ and $\mathrm{MeOH}(30 \mathrm{ml})$, then $21(0.5 \mathrm{mmol})$ was added and the $\mathrm{pH}$ was adjusted to 8.0. The reaction mixture was strirred at room temperature for 48 hours, the precipitated product was filtered off, washed with water and $50 \%$ aquoeus methanol and dried in a vacuum desiccator. The physico-chemical data and NMR spectral characteristics of $\mathbf{2 2}$ and $\mathbf{2 3}$ are given in Tables 4 and 5, respectively.

\section{Antibacterial Activity Testing}

Bacterial Strains

The antibacterial activities of the preparations and their derivates were measured on B. subtilis ACTC 6633, methicillin-sensitive S. aureus ACTC 29213 (MSSA), methicillin-resistant $S$. aureus ACTC 33591 (MRSA), methicillin-resistant $S$. epidermidis IMMSU12333/05 (MRSE), vancomycin- and teicoplanin-sensitive E. faecalis ACTC 29212 (VSEF), and vancomycin-resistant but teicoplanin-sensitive E. faecalis ACTC 51299 (VREF) strains. The confirmation of the presence and absence of the $\operatorname{van} A \sim B$ and $m e c A$ genes was done as previously described $[27,28]$.

Susceptibility Test

In all cases, except for linezolid, the efficacy of the antimicrobials was determined with the broth micro dilution method according to the NCCLS guideline [29]. Bacterial strains were grown on $5 \%$ bovine blood agar plates at $35^{\circ} \mathrm{C}$ overnight. Appropriate numbers of colonies were suspended in physiological saline in order to reach the density of 0.5 McFarland for inoculation.

Stock solutions of different concentrations of the antimicrobials were prepared in either distilled water or water-methanol $(1: 1)$ or in water-DMSO $(1: 1)$ depending on the solubility of the given preparation. These were two-fold serially diluted from 256 to $0.5 \mu \mathrm{g} / \mathrm{ml}$ in cation-adjusted Mueller-Hinton broth then $100 \mu \mathrm{l}$ of each dilution was transferred into microplate's holes. Inoculation occurred with $10 \mu \mathrm{l}$ of each of the bacterial suspensions. Incubation was performed at $35^{\circ} \mathrm{C}$ for 18 hours and reading of minimal inhibitory concentration (MIC) was made with the naked eyes on a mirror.

Solvents were also tested for inhibition of bacterial growth. None of them exerted bacteriostatic effect at the concentration used.

MICs for linezolid were determined with the E-test on cation-adjusted Mueller-Hinton agar plates according to the instructions of the manufacturer (AB Biodisk, Solna, Sweden).

Acknowledgement The authors thank the Hungarian Academy of Sciences and the National Scientific Research Found (Grant No.: OTKA TO46744 and TO46186) for financial support, Nikolett Mihala (Research Group for Peptide Chemistry of the Hungarian Academy of Sciences, Budapest) for her help in the deglycosidation experiments, and Dr. Sándor Kéki (Department of Applied Chemistry, University of Debrecen) for recording the mass spectra. The skillful technical assistance of Ms. Natasa Pesti (Institute of Medical Microbiology, Semmelweis University) is highly appreciated. We are indebted to Olga Miroshnikova (Gauze Institute of New Antibiotics, Moscow) for the preparation of aglyco-teicoplanin.

\section{References}

1. Sztaricskai F, Bognár R. The chemistry of the vancomycin group of antibiotics in recent developments in the chemistry of natural carbon compounds. Vol. 10: 91-209, Szántay Cs, ed., Akadémiai Kiadó, Budapest (1984)

2. Nicolaou KC, Boddy CN, Bräse S, Winssinger N. Biology and medicine of the glycopeptide antibiotics. Angew Chem Int Ed 38: 2096-2152 (1999)

3. Sztaricskai F, Pelyvás FI. Chemistry of carbohydrate components in glycopeptide antibiotics. Drugs and Pharm.Sci., Nagarajan R, ed., Marcel Dekker Inc. New York, 63: 105-193 (1994)

4. Williams DH, Bardsley B. The vancomycin group of 
antibiotics and the fight against resistant bacteria. Angew Chem Int Ed 38: 1172-1193 (1999)

5. Wanner J, Tang O, Mclomas CC, Crowley BM, Jiang W, Moss J, Boger DL. A new improved method for deglycosidation of glycopeptide antibiotics exemplified with vancomycin, ristocetin and ramoplanin. Bioorg Med Chem Lett 13: 1169-1173 (2003)

6. Ellestad GA, Leese RA, Morton GO, Barbatschi F, Gorew E, McGahren WJ. Avoparcin and epiavoparcin. J Am Chem Soc 103: 5522-5524 (1981)

7. Herrin TR, Thomas AM, Perun IJ, Mao JC, Fesik SN. Preparation of biologically active ristocetin derivatives replacements of the 1'-amino group. J Med Chem 28: 1371-1375 (1985)

8. Tietze LF, Arlt M, Beller M, Glüsenkamp KH, Jäde E, Rajewsky MF. Squaric acid diethyl ester: a new coupling reagent for the formation of drug biopolymer conjugates. Synthesis of squaric acid ester amides and diamides. Chem Ber 124: 1215-1221 (1991)

9. Tevyashova A, Sztaricskai F, Batta Gy, Herczegh P, Jeney A. Formation of squaric acid amides of anthracycline antibiotics. Synthesis and cytotoxic properties. Bioorg Med Chem Lett 14: 4783-4789 (2004)

10. Sztaricskai F, Sum A, Roth E, Pelyvás FI, Sándor Sz, Batta Gy, Herczegh P, Reményi J, Miklán Zs, Hudecz F. A new class of semisynthetic anthracycline glycoside antibiotics incorporating a squaric acid moiety. J Antibiot 58: 704-714 (2005)

11. Cooper RDG, Snyder NJ, Zweifel MJ, Staszak MA, Wilkie SC, Nicas TI, Mullen DL, Butler ThF, Rodriguez M J, Huff BE, Thomspson RC. Reductive alkylation of glycopeptide antibiotics: synthesis and antibacterial activity. J Antibiot 49: 575-581 (1996)

12. Kahne D, Leimkuhler C, Lu W, Walsch Ch. Glycopeptide and lipoglycopeptide antibiotics. Chem Rev 105: 425-448 (2005)

13. Mu YQ, Nodwell M, Pace JL, Shaw J-J, Judice JK. Vancomycin disulfide derivatives as antibacterial agents. Bioorg Med Chem Lett 14: 735-738 (2004)

14. Kobrin MB, Katrukha HS, Fedorova GB. Preparation and properties of derivatives at the amino group of ristocetin aglycone. J Antibiot 42: 1441-1442 (1989)

15. Pavlov AYu, Olsuf'eva EN, Miroshnikova OM, Reznikova MI, Lazhko EI, Malabarba A, Ciabatti R, Preobrazhenskaya MN. Synthesis and antibacterial activity of nonnatural aglycones of glycopeptide antibiotics of the vancomycin group. Russian J Bioorg Chem 23: 383-393 (1997)

16. Printsevskaya A, Solovieva SE, Olsufjeva EN, Mirchink EP, Isakova EB, DeClerq E, Balzarini J, Preobrazhenskaya MN. Structure-activity relationship studies of a series of antiviral and antibacterial aglycon derivatives of the glycopeptide antibiotics vancomycin, eremomycin, and dechloroeremomycin. J Med Chem 48: 3885-3890 (2005)
17. Hawkes GE, Molinari H, Singh S, Lian LY. A N-15 NMR study of intermolecular interactions between vancomycin and Ac-D-Ala-D-Ala. J Magnetic Resonance 74: 188-192 (1987)

18. Molinari H, Pastore A, Lian LY, Hawkes GE, Sales K. Structure of vancomycin and a vancomycin/D-Ala-D-Ala complex in solution. Biochemistry 29: 2271-2277 (1990)

19. Batta Gy, Sztaricskai F, Makarova MO, Gladkikh EG, Pogozheva VV, Berdnikova TF. Backbone dinamics and amide proton exchange at the two side of eremomycin dimer by ${ }^{15}$ NMR. Chem Comm 501-502 (2001)

20. Malabarba A, Ferrari P, Gallo GG, Kettenring J, Cavalleri B. Teicoplanin, antibiotics from Actinoplanes teichomyceticus Nov. sp. J Antibiot 39: 1430-1442 (1986)

21. Bongini A, Feeney J, Williamson MP, Williams DH. Assignment of the carbon-13 spectrum of vancomycin and its derivatives. J Chem Soc Perkin Trans 2 201-206 (1981)

22. Williamson MP, Williams DH. A carbon-13 nuclear magnetic esonance study of ristocetin A and B and their derivatives. J Chem Soc Perkin Trans 1 1483-1491 (1981)

23. Batta Gy, Sztaricskai F, Kövér KE, Rüdel C, Berdnikova TF. NMR Study of eremomycin and its derivatives. Full ${ }^{1} \mathrm{H}$ and ${ }^{13} \mathrm{C}$ assignment, motial behaviour, dimerization and complexation with Ac-D-Ala-D-Ala. J Antibiot 44: 1208-1221 (1991)

24. Loll PJ, Axelsen PH. The structural biology of molecular recognition by vancomycin. Annual Review of Biophysics and Biomolecular Structure 29: 265-289 (2000)

25. ACD Software; Toronto, ON, Canada, M5H 3V9; www.acdlabs.com

26. Boger DL. Vancomycin, teicoplanin and ramoplanin: synthetic and mechanistic studies. Med Research Reviews 21: 356-381 (2001)

27. Knausz M, Ghidán Á, Grossato A, Rozgonyi F. Rapid detection of methicillin resistance in teicoplanin-resistant coagulase-negative Staphylococci by a penicillin-binding protein 2' latex agglutination method. J Microbiol Methods 60: 413-416 (2005)

28. Ghidán Á, Jeney Cs, Maródi LCs, Csiszár K, Rozgonyi F. PCR detection of the vanA gene in a vancomycin-resistant Enterococcus faecalis clinical isolate from Hungary. J Antimicrob Chemother 46: 325-327 (2000)

29. National Committee for Clinical Laboratory Standards Performance Standards for Antimicrobial Susceptibility Testing. 12th Informational supplement M100-S12. NCCLS, Wayne, PA. USA (2002)

30. Ford ChW. In: Oxazolidinones: a new class of antibiotics. Ed., Moellering $\mathrm{R}$ Jr., 8th International Congress on Infections Diseases Industry-Sponsored Symposium, (Pharmacia and Upjohn), Boston, May 17 (1998)

31. Goddard TD, Kneller DG. SPARKY 3, University of California, San Francisco 